\title{
EL CAPITALISMO ARGENTINO EN LA POSCONVERTIBILIDAD: \\ UN ANÁLISIS DE LOS ALCANCES DEL DESEMPEÑO \\ PRODUCTIVO Y DE SU RELACIÓN CON LAS POLÍTICAS CIENTÍFICAS Y TECNOLÓGICAS
}

\author{
Rodrigo D. Avendaño \\ avendanord@hotmail.com \\ Fernanda Di Meglio \\ megliofernanda@hotmail.com
}

Universidad del Centro de la Provincia de Buenos Aires, Argentina

\section{RESUMEN}

El artículo analiza las principales transformaciones ocurridas en la Argentina en materia productiva y tecnológica en la década transcurrida desde el colapso del régimen de convertibilidad en diciembre de 2001. Para ello se trabaja a dos niveles analíticos diferenciales. En primer término, un análisis de la trayectoria del sector manufacturero, enfatizándose sobre la existencia de una nueva dinámica de crecimiento que ha revertido la tendencia desindustrializadora desarrollado durante el cuarto de siglo que le precedió $\mathrm{y}$, al mismo tiempo, la continuidad de algunos de sus sesgos regresivos más críticos. En segundo lugar, se analizan las principales transformaciones ocurridas en materia de políticas científico-tecnológicas, el fortalecimiento de las capacidades estatales y la puesta en funcionamiento de novedosos instrumentos de promoción e incentivo para la formación de recursos humanos y de actividades productivas intensivas en conocimiento. Se argumenta que ese conjunto de transformaciones permiten concebir la existencia de una nueva armonía en la configuración de las relaciones entre desempeño productivo y política científico-tecnológica.

Palabras clave: Ciencia y tecnología, Política económica, Producción, Argentina. 


\title{
THE ARGENTINE CAPITALISM IN THE POST- CONVERTIBILITY: \\ AN ANALYSIS OF THE SCOPE OF PRODUCTION \\ PERFORMANCE AND ITS RELATIONSHIP WITH SCIENCE AND TECHNOLOGY POLICIES
}

\begin{abstract}
The article analyzes the main transformations occurred in Argentina in production and technology in the decade since the collapse of the convertibility regime in December 2001. This is carried out at two differential analytical levels. First, an analysis of the trajectory of the manufacturing sector, emphasizing the existence of a new growth dynamic that has reversed the desindustrializing trend developed during the quarter of a century that preceded it and at the same time, the continuity of some of their critical regressive bias. Second, the major transformations in the scientific-technological policies, the strengthening of the state capacity and the commissioning of new instruments for the promotion and incentive to the development of human resources and knowledge intensive production activities are analyzed. It is argued that this set of transformations allow conceive of a new harmony in shaping relationships between production performance and scientific-technological policy.
\end{abstract}

Keywords: Science and technology, economic policy, Production, Argentina. 


\section{INTRODUCCIÓN}

La caída del régimen de convertibilidad en enero de 2002 y la mega-devaluación de la moneda nacional, inauguraron una nueva fase del desenvolvimiento del capitalismo argentino ${ }^{1}$. Una serie de reconfiguraciones en múltiples planos se han dado lugar en lo que ha sido llamado la posconvertibilidad argentina, destacándose la revitalización de la producción como núcleo dinámico de la acumulación y de la organización de la vida social ${ }^{2}$ y la recuperación del Estado en su carácter de agente legítimo, y más aún necesario, en el apuntalamiento de la dinámica del crecimiento, luego de décadas de ajuste y achicamiento justificado en las supuestas virtudes neutrales de las fuerzas del mercado.

Es en el seno de esas transformaciones que se presencia un renacer del papel de la ciencia, la tecnología y la innovación en la agenda política nacional, como pieza clave para el desarrollo. Es que si bien la Ciencia y la Tecnología no estuvieron ausentes de todo plano en la década de 1990 , poseen un nuevo carácter en el marco de un proceso de crecimiento económico, que bajo las nuevas condiciones macroeconómicas, vuelve a tener a la producción, y en ella a la expansión industrial, como núcleo dinámico del ciclo ascendente. La reversión de la tendencia desindustrializadora habilitada por una nueva dinámica de crecimiento sectorial, de un lado, y el reimpulso de la política estatal tendiente a la reconstrucción de las capacidades científicas y tecnológicas, por otro, se presentan así como datos fundamentales del conjunto de rupturas abiertas desde la descomposición neoliberal en la Argentina.

1 El régimen monetario de convertibilidad quedó establecido bajo presidencia de Carlos Menem por la Ley N. 23.928 del Congreso Nacional del 27 de marzo de 1991 y mantuvo su vigencia hasta el 6 de enero de 2002 bajo presidencia de Eduardo Duhalde, momento de inicio de lo que en este escrito se denomina como período de la posconvertibilidad a partir de la devaluación del $40 \%$ del peso argentino. Instrumentado como herramienta anti-inflacionaria, la convertibilidad consistió en la paridad cambiaria fija entre la moneda nacional y la estadounidense a razón de un dólar estadounidense por cada Peso argentino convertible con garantía de un dólar norteamericano bajo depósito del Banco Central de la República Argentina (BCRA) por cada peso en circulación.

2 La preeminencia de mecanismos de valorización financiera sobre la actividad productiva resulta una de las dinámicas más significativas del desempeño del capitalismo argentino en el período que va desde la irrupción de la última dictadura militar en 1976 hasta el final del régimen de convertibilidad en enero de 2002 (Basualdo 2010). 
Habiendo transcurrido ya más de una década desde que esas dos dinámicas se han estado desplegando, se hace preciso indagar acerca de los alcances, y eventuales límites, del proceso de reconstrucción del aparato productivo y del sistema de Ciencia y Tecnología (CyT), centrando la atención sobre la contribución de sus articulaciones hacia el despliegue de un cambio estructural en el desarrollo económico argentino. Concretamente, se propone en el presente trabajo indagar respecto a las existentes y potenciales dinámicas de relacionamiento de las transformaciones ocurridas en los planos del desempeño económico-productivo y de la política científicotecnológica tecnológica en el período de la posconvertibilidad.

En función de ese objetivo, el artículo se organiza en cuatro apartados principales. En primer término, se esboza una aproximación analítica de las relaciones existentes entre el desarrollo económico, las capacidades tecnológicas y las políticas estatales en la materia. En segundo lugar, se realiza una caracterización del derrotero productivo y tecnológico neoliberal, con énfasis en aquellos fenómenos cuyos mayores niveles de coherencia se condensan al amparo delas políticas deapertura, liberalización, desregulación y sobrevaluación cambiaria durante la década de 1990. En tercer lugar, se propone recorrer las transformaciones ocurridas desde el abandono del régimen de convertibilidad en materia productiva, enfatizándose sobre la nueva dinámica de expansión del sector manufacturero, sus logros y sus apreciables limitaciones en términos de su perfil de especialización. En cuarto término se abordan las transformaciones apreciables en materia de política científico tecnológica, destacándose la recuperación del rol y de las capacidades estatales para la promoción de recursos científicos locales y en la instrumentación de políticas de promoción de actividades productivas intensivas en ciencia y tecnología. Se presenta aquí además un análisis de la evolución de la industria del software donde esos dos planos de transformaciones (desempeño productivo y política estatal en СуT) ha reportado resultados auspiciosos en vistas de la superación de las todavía presentes invariantes neoliberales en la estructura productiva nacional. Finalmente se proponen una serie de conclusiones, poniendo en evidencia la existencia de una nueva armonía en las relaciones entre el comportamiento productivo y la política estatal en ciencia y tecnología.

\section{DESARROLLO, INDUSTRIA Y POLÍTICA DE CIENCIA, TECNOLOGÍA E INNOVACIÓN}

En América Latina, el arraigo de un ideario -tanto en el seno del debate académico como en el referido a la determinación de las agendas de política estatal- que enfatiza los vínculos existentes entre las capacidades científicas y tecnológicas generadas endógenamente y el objetivo primordial del 
desarrollo económico-social se remonta a la década de 1950 al calor de los debates sobre las trayectorias de industrialización de los países de la región. Aunque con matices no menores según el interlocutor de que se trate, desde momentos tempranos se posicionó en estrechas relaciones de pertenezco al desarrollo de la CyT, el crecimiento económico, el desarrollo industrial y la distribución progresiva del ingreso ${ }^{3}$. Autores como Oscar Varsavsky (1969), representante de la posición más radicalizada en que estas ideas cristalizaron, incluso sostuvo que la contribución de la ciencia y la tecnología al desarrollo productivo de los países dependientes debía lograrse sobre la construcción de una agenda y repertorio sui generis, donde el énfasis de la política tecnológica debía estar centrado en contribuir a dar respuestas a demandas impostergables de las mayorías populares.

El soporte ordenador de toda política estatal de CyT es un determinado posicionamiento sobre el desarrollo deseable del país (Porta y Bianco 2004, Cimoli et al. 2007) que ha de ser cristalización del equilibrio de fuerzas sociales en el aparato estatal en un momento histórico determinado. Siguiendo el planteamiento de Bianco y Porta (2004), de los diferentes diagnósticos y miradas sobre los problemas del desarrollo económico argentino emergen un conjunto de respuestas que orientan las prioridades estratégicas de la política económica y productiva que interpelan de muy diversos modos al sistema de CTI.

La Argentina de la década de 1940 ubicó por vez primera al crecimiento industrial como eje ordenador del proceso de reproducción social, su centralidad estratégica para el modelo de desarrollo residía en su carácter de soporte material y político de una dinámica que resolvería el cuadro histórico de atraso económico y desigualdad social. Los alcances y límites del proyecto de industrialización por sustitución de importaciones (ISI) en la Argentina son aún hoy objeto de debate, sin embargo existe consenso respecto a sus efectos positivos en la diversificación de la estructura productiva nacional, su rol catalizador de mejoras en las condiciones de vida de las mayorías populares y de una dinámica de movilidad social ascendente de la cual era su soporte material indispensable. La problematización del rol del sistema de CyT y de la política pública en la materia como puntos angulares del desarrollo industrial en las décadas de 1950 y 1960 y sus relaciones con las necesidades del aparato productivo merecen un momento de detenimiento, pues de esas experiencias es posible extraer un conjunto de claves para el análisis de lo sucedido en la primera década del

3 Entre ellos es posible mencionar al conjunto de intelectuales pertenecientes al estructuralismo latinoamericano cuyas ideas anclaron en la Comisión Económica para América Latina y el Caribe (CEPAL) conducida por Raúl Prebisch, e intelectuales de envergadura como Jorge Sábato y Natalio Botana (1968), Oscar Varsarvsky (1969). 


\section{siglo XXI ${ }^{4}$.}

En la Argentina, el desarrollo primero -en la década de 1940- de ramas industriales productoras de bienes salarios no durables y luego -en las décadas de 1950 y 1960- de ramas productoras de bienes no durables (automotriz) y de base (siderurgia, celulosa, química y petroquímica), se dio lugar bajo una dinámica cíclica de corto plazo, denominada stop and go, donde la fase ascendente, que posibilitaba la expansión del empleo, los salarios y el mercado interno; era seguida por estrangulamientos del sector externo que derivaban en ajustes devaluatorios, disminución de la tasa de crecimiento del producto industrial, contracción del empleo, los salarios y el mercado interno (Basualdo 2006).

Las restricciones a la continuidad y profundización del desarrollo industrial tuvieron asiento en las debilidades de una estructura productiva desarticulada y tecnológicamente dependiente (Diamand 1985). Es que, en la medida en que el producto industrial crecía se incrementaban en una proporción ascendente los requerimientos de divisas necesarios para el pago de las importaciones de insumos complejos y tecnología, divisas que el sector industrial por su escaza capacidad para competir en el mercado mundial no proveía y que las exportaciones primarias no podía enfrentar debido al deterioro de sus precios internacionales. Como consecuencia de ello, la dinámica de crecimiento industrial encontraba fuertes trabas a su continuidad por las frecuentes restricciones del sector externo originadas en los desbalances de la cuenta corriente.

Pese que el proceso de industrialización habilitó el surgimiento de industrias tecnológicamente complejas para la época, como la metalmecánica, los instrumentos y equipos, etc., que en el período 1964-1974 coadyuvaron a morigerar las tendencias recesivas en las fases descendentes del ciclo, en términos generales se trató de industrias protagonizadas por capitales de pequeño porte subordinados técnica y

4 En marco de vigencia de los modelos de desarrollo sustentados en la industrialización por sustitución de impostaciones (ISI), que con mayor o menor envergadura y profundidad tuvieron lugar en los países de la región a la salida de la crisis capitalista mundial de 1930, comenzó a emerger a mediados del siglo pasado la naciente institucionalidad de ciencia y tecnología. Promovida desde organismos internacionales como la Organización de Estados Americanos y la Unesco en esta primera etapa del diseño institucional de CyT se produce el nacimiento en varios países latinoamericanos de los Consejos de Ciencia y Tecnología. En 1951 en Brasil, el Consejo Nacional de Desarrollo Científico y Tecnológico (CNPq); en 1958 en Argentina, el Consejo Nacional de Investigaciones Científicas y Técnicas (CONICET); en 1970 en México, el Consejo Nacional de Ciencia y Tecnología (CONACYT). 
económicamente a los ciclos de acumulación de empresas transnacionales (ETs) (Azpiazu, Basualdo y Khavisse 2004). La protección del mercado interno generaba pocas presiones competitivas al capital extranjero para asumir un rol innovador dinámico en el ámbito local, siendo el comportamiento tecnológico preponderante el de la adaptación de desarrollos de procesos y productos importados, lo que en la generalidad de los casos se encontraban en situación de obsolencia al estado del arte de los países desarrollados, cerrándose con ello las puertas de un desarrollo competitivo del tejido industrial local (Cimilo et al. 1973).

En ese cuadro, la política científica y tecnológica, tributaria ampliamente difundido en los países industriales avanzados paradigma lineal de la innovación, acusó un marcado desacople con las necesidades del aparato productivo. El paradigma lineal concibe a la innovación como el producto relativamente automático de un proceso que tiene su punto de partida en el desarrollo de la ciencia básica, seguido por la investigación aplicada, el desarrollo de nuevas tecnologías y dando por último lugar a innovaciones aplicadas en el ámbito de la producción. El énfasis de la naciente política tecnológica en la ciencia aplicada reportó resultados notables en el ámbito científico ${ }^{5}$, sin embargo escasa fue su contribución a sanear los visibles problemas tecnológicos de la matriz industrial que el modelo de desarrollo aspiraba a consolidar.

El dramático quiebre de la estrategia de industrialización desarrollado a partir de la última dictadura militar (1976-1983), con una deliberada política de agresión al sector, derivó en el reflujo y desaparición de las incipientes capacidades tecnológicas internas. Según la teoría económica ortodoxa en curso, la simple liberalización y apertura de la economía y la penetración del capital extranjero implicaría la incorporación de patrones tecnológicos ubicados la frontera internacional, cerrándose con ello la brecha de productividad entre países desarrollado y en desarrollo ${ }^{6}$.

En el marco de un escenario macroeconómico de mayor apertura y liberalización, y ante el visible fracaso del diagnóstico arriba descripto, en la década de 1990 se produce la emergencia de un enfoque alternativo para el análisis de las relaciones entre ciencia, tecnología e innovación (CTI) y el desarrollo económico, denominado como la teoría del Sistema Nacional de Innovación (SNI). La teoría del SNI, tributaria de las teorías

5 Representativo de ello es la obtención de tres premios nobeles argentinos en ciencias.

6 Las consecuencias en términos del diseño y estilo de política de CyT a la que esa concepción dio lugar se discutirán en los apartados siguientes. 
económicas evolucionista e institucionalista ${ }^{7}$, se posiciona en un espacio conceptual distinto tanto del asumido por quienes observan la necesidad de la autonomía tecnológica absoluta como de aquellos que conciben el rol de los países en desarrollo como meros asimiladores de desarrollos extranjeros.

El enfoque del SNI, referenciado en las experiencias de rápido desarrollo industrial de países del sudeste asiático (Corea del Sur y Taiwán) da cuenta de la intervención en esos procesos de la combinación de insumos tecnológicos importados con esfuerzos domésticos y concibiendo al desarrollo como un proceso no lineal en el que intervienen la transformación de la estructura industrial, la acumulación de capacidades tecnológicas y la evolución de las políticas en materia de innovación (Cimoli y Dosi 1995). La innovación y el avance tecnológico surgen cuando las empresas, que actúan de acuerdo con los mecanismos de mercado, y las instituciones, cuyo comportamiento está determinado por incentivos que no responden a los mecanismos de mercado, se acaban interconectando en un ámbito regulado por normas y leyes apropiadas. Se trata de un enfoque donde la atención es puesta en las interacciones que provocan el surgimiento de capacidades tecnológicas producto al mismo tiempo de los incentivos creados por la demanda y los impulsos de la política tecnológica (Freeman 1993, Nelson 1993, Cimoli y Dosi 1995).

Las recomendaciones de políticas desde la teoría del SNI apuntan a la coordinación de las políticas económicas y de ciencia y tecnología con el aparato productivo, donde los incentivos de la política de innovación sean al mismo tiempo resultado de la visualización de prioridades estratégicas para el desarrollo de determinadas actividades dinámicas en el mercado mundial como el producto de la incorporación de las demandas tecnológicas que emergen de los propios agentes privados. Derivado de esta posición pragmática respecto al nuevo escenario impuesto por la globalización, el objetivo del desarrollo será vehiculizado por un robustecimiento del SNI que apunte a la progresiva participación de las economías en desarrollo en los eslabones más intensivos en tecnología y conocimientos de las cadenas globales de valor (CGV), alejándose entonces de las actividades basadas en ventajas comparativas estáticas (recursos naturales y salarios bajos), donde el precio es el factor decisivo de competitividad en condiciones de economía abierta (Jeffrey et al. 2002)8 . En palabras de Cimoli,

7 Una reconstrucción de la trayectoria general de este marco analítico puede encontrarse en Rincón Castillo (2004).

8 El rol de la dotación de recursos naturales de los países latinoamericanos, como ventana de oportunidad o como obstáculo, para lograr su progresiva incorporación 
[...] la densidad de los vínculos y las transferencias tecnológicas, que determinan el grado de complejidad de la estructura de producción y que afecta a la capacidad competitiva y a la posibilidad de reaccionar ante las perturbaciones exógenas, dependen de los patrones de especialización y, en las economías abiertas, del posicionamiento en las redes mundiales (2007: 14).

El patrón de especialización adoptado por un país moldea en un determinado sentido la estructura productiva, lo cual influye sobre el tipo de demandas de ciencia y tecnología que éste genera, siendo la coordinación y la co-evolución de las políticas macroeconómicas, industrial y científicotecnológica el elemento estructurante del sendero de modernización y difusión de conocimientos ${ }^{9}$. En consecuencia, la configuración de una política estatal en CTI y su incidencia sobre la robustez del SNI puede adquirir múltiples morfologías, con grados variables de intervención estatal en el direccionamiento del comportamiento tecnológico del sector privado, con diseños diferenciales de los instrumentos de promoción tecnológica y de articulación del sistema científico público y el aparato productivo, con múltiples destinatarios (sectores, tramas productivas, empresas, regiones); al tiempo que desarrollando variantes - en intensidad y profundidad- de sinergias público-privadas bajo formas institucionales particulares.

En este punto se cree necesario incorporar a la reflexión una categoría analítica, la de modelo de desarrollo, que si bien de larga tradición en los análisis de la sociología del desarrollo latinoamericano, no siempre ha sido incorporada a los estudios sobre la ciencia y la tecnología. Sin intenciones de realizar una genealogía de la categoría y sus usos, es preciso decir que el patrón de inserción internacional que estructuran regularidades sobre la matriz productiva y sobre el estilo y forma que asumen las relaciones entre ésta y el entramado institucional de CyT, tiene el anclaje inmanentemente político del modelo de desarrollo, entendido como:

en eslabones con altos requerimientos de conocimiento y tecnología de las CGV constituye uno de los principales puntos debate en el seno de esta corriente. Véase al respecto los artículos de Pérez (2012) y las respuestas de Barletta et al. (2013) y Rocha (2012).

9 Así por ejemplo, la apertura y liberalización indiscriminadas de las economías latinoamericanas a la salida de la crisis de la deuda de la década de 1980, llevaron a la profundización de un patrón de inserción industrial fundado en las ventajas comparativas estáticas (recursos naturales y mano de obra), limitando "implícitamente el posible efecto de estímulo positivo de alcanzar los niveles tecnológicos más adelantados, generado por la liberalización del comercio y el aumento de la competencia” (Cimoli 2007: 10). 
[...] una forma idealizada y orientada hacia el futuro de lo que se quiere y se desea. El modelo de desarrollo no es un proceso histórico como el modo, pero sí un proyecto histórico. Su carga moral es inmediata y explícita (...) El modelo de desarrollo es un programa de acción en devenir, es el desarrollo en su dimensión transitiva. Cualquier modelo de desarrollo es eminentemente político (Roig 2008: 88).

El sendero de desarrollo económico perfilado y proyectado, es decir el modelo de desarrollo, posee un conjunto de fundamentos que gravitan, aunque con grados variables de coherencia, en torno a una matriz teórica e ideológica que le es propia y que implican una diversidad de miradas sobre los fundamentos, caracteres y objetivos que deberían conducir a las capacidades de CTI producidas por un país. El soporte ordenador de toda política estatal de CyT es un determinado posicionamiento del Estado sobre el desarrollo deseable (Porta y Bianco 2004) ${ }^{10}$; que ha de ser cristalización históricamente particular del equilibrio de fuerzas políticosociales en el aparato estatal ${ }^{11}$.

10 Los autores corroboran la existencia de cuatro miradas principales respecto de los senderos posibles del desarrollo económico argentino, sostenidos en diferentes matrices teóricas e ideológicas que implican diferentes concepciones y relaciones entre el sistema productivo y el sistema de CyT, a saber: la concepción neoliberal (en mayor parte vigente en la década de 1990), la autárquica, la neo-desarrollista de base industrial y la neodesarrollista de base agraria. Fundamentalmente las diferencias respecto a la concepciones del desarrollo giran en torno las fuentes de crecimiento del producto (mercado interno o externo), las características de la especialización productiva (fundada en ventajas comparativas naturales- heredadas o en ventajas competitivas dinámicas), las formas de regulación y coordinación (primacía del mercado o del Estado en la dirección y asignación de recursos), los agentes líderes del proceso de acumulación (empresas transnacionales, gran capital local, pequeñas y medianas empresas, o redes empresariales). En ese orden, las relaciones con el sistema de $\mathrm{CyT}$ de las diferentes posiciones implican: provisión extranjera de paquetes tecnológicos cerrados y un sistema científico público centrado en el desarrollo de la ciencia básica y semi básica requerida por el sector privado; centralidad de las agencias científicas en la producción de conocimientos y tecnologías trabajointensivas transferibles a PYMEs; conformación de un fuerte SNI sostenido en un fortalecimiento de la institucionalidad estatal de CyT con fuertes articulaciones con la estructura industrial que debe apuntar al desarrollo de actividades con competitividad internacional basada en diferenciación de productos y no en precios; y un sistema de CTI centrado en la provisión tecnológica al sector agroalimentario destinadas al desarrollo de competitividades genuinas en el mercado mundial (Porta y Bianco 2004: 51-53).

11 Esta concepción del Estado como cristalización histórica de fuerzas político-sociales es tributaria de la teoría del Estado de Nicos Poulantzas (2007) y de la teoría regulacionista (Boyer y Saillard 1996). 
Ahora bien, la reversión de la tendencia desindustrializadora en la Argentina a partir de la ruptura de la convertibilidad en enero de 2002 junto al reimpulso de la política estatal tendiente a la reconstrucción de las capacidades científicas y tecnológicas locales desarrolladas durante las presidencias de Néstor Kirchner (2003-2007) y Cristina Fernández de Kirchner (2007-2015), se han presentado como objetivos estratégicos de las políticas de desarrollo implementadas y como pilares de una trayectoria deseable que auspicia la necesidad del crecimiento económico-productivo compatible con la expansión del empleo formal, con la expansión de la demanda dinamizada por el consumo interno, redundando ello en un movimiento de distribución progresivamente más igualitario del ingreso nacional. Aquí nuevamente es relevante la diferenciación sugerida por Roig (2008) del modelo de desarrollo respecto al modo de desarrollo. El modo de desarrollo, a diferencia del modelo, debe entenderse como la trayectoria histórica efectivamente desarrollada por un capitalismo nacional, el modo en que sus conflictos y contradicciones se han institucionalizado en un período determinado, lo cual puede asumir grados diversos de coherencia y conflictividad con el sendero idealizado o proyectado. En palabras del autor:

[...] podremos definir un modo de desarrollo como el proceso de transformación de las instituciones que surgen de la dinámica de los conflictos estructurales. Cada modo de desarrollo es singular ya que los conflictos estructurales se expresan históricamente en forma singular en cada ámbito nacional. No hay teleología en el modo de desarrollo aunque si la hay (Roig 2008: 237).

Como producto de lo anterior, es esperable que a la hora de analizar el modo de desarrollo transcurrido por el capitalismo argentino durante la primera década del siglo XXI, se puedan apreciar distancias o brechas respecto a aquello que el modelo de desarrollo enunció como horizonte, al tiempo de observar la manera en que esas tensiones entre lo esperado y lo acontecido podrían institucionalizarse en un nuevo movimiento de síntesis del modelo de desarrollo. Específicamente interesa en este escrito indagar respecto a las trayectoria productiva y tecnológica del capitalismo argentino a la salida de la convertibilidad, el modo de desarrollo, enfatizando lo que se presentarán como un conjunto de tensiones entre las aspiraciones y el devenir del proceso de recuperación económica sostenido en la reindustrialización con distribución progresiva del ingreso con asiento en un conjunto de restricciones originadas por limitaciones tecnológicas del aparato productivo que persisten como invariantes del derrotero neoliberal. En virtud de ello, se pone de manifiesto la necesidad de una articulación coordinada de las políticas de CTI con el aparato 
productivo como condición necesaria para el avance hacia ese objetivo estratégico. Se podrá al mismo tiempo observar que la articulación de políticas científicas y tecnológicas con demandas originadas en por el sector productivo en un caso específico, la industria de bienes y servicios de software, constituye un caso prefigurativo de ese nuevo horizonte deseable.

\section{RAZGOS Y LEGADOS PRODUCTIVOS Y TECNOLÓGICOS DEL CAPITALISMO NEOLIBERAL ARGENTINO}

El proceso de reestructuración de la economía argentina en la década de 1990 constituyó el eslabón superior del ciclo abierto por la ruptura del modelo de industrialización sustitutiva impuesto por la última dictadura militar desde 1976 (Azpiazu y Schorr 2010). Sin embargo, el conjunto de mutaciones regresivas, bien condensadas en la proclama neoliberal denominada como consenso de Washington, adquirieron un grado de coherencia y profundidad mundialmente inédito. La dimensión de las transformaciones acaecidas en esa década, marcan el escenario sobre el cual parte la expansión que tiene lugar a la salida de la convertibilidad; a su vez que la reversión de sus aspectos más regresivos constituyen, aún hoy, los principales desafíos del nuevo patrón productivo, ponderándose así la potencialidad del direccionamiento de la política estatal CyT como herramienta estratégica de transformación.

La industria en general y las firmas orientadas al mercado interno en particular, sufrieron los mayores costos de la sobrevaluación monetaria y de una indiscriminada apertura a la competencia internacional, profundizándose el proceso de desindustrialización iniciado en 1976 ${ }^{12}$; una reducción del coeficiente de industrialización del 18,2\% al 15,4\% entre 1993 y 2001. La reducción de la gravitación de la industria siguió una trayectoria independiente de los momentos del ciclo económico. Así cuando superados los efectos de la crisis mexicana de 1994 mientas la economía argentina consiguió tres años de crecimiento ininterrumpido (1996-1998) a una tasa anual acumulativa del 5,8\%, el sector industrial lo hizo a una tasa idéntica pero después de haber caído un 7,1\% en 1995 (cuando en ese año el Producto Bruto Interno, PBI, global decreció 2,8\%). Por su parte, durante la crisis final del modelo de convertibilidad entre 1998 y 2002, mientras el PBI global se contrajo en promedio un $-4,8 \%$ anual, el PBI industrial lo hizo a una tasa del $-7,52 \%$ anual. El movimiento tendencial por el cual durante las fases ascendentes del ciclo económico el crecimiento industrial es modesto respecto al del promedio de la economía, mientras que en las

12 Durante la última dictadura militar se redujo más de cuatro puntos porcentuales la participación del sector manufacturero en el PBI, pasando del 28,3\% en 1974 al $23,8 \%$ en 1983. 
fases recesivas la contracción fabril es mucho más profunda y acelerada, da cuenta del carácter regresivo de la pérdida de participación de la industria en el producto global. Ello contrasta claramente con aquellas visiones que observaron en el mayor peso relativo de los servicios y del sector financiero, un símbolo de la modernización de la estructura económica nacional ${ }^{13}$.

La reestructuración productiva y tecnológica regresiva (Nochteff 1991, Azpiazu y Nochteff 1995) se sostuvo bajo el supuesto de que la apertura económica y el arribo masivo de capitales y tecnología importada, cerraría la brecha de productividad con las economías centrales. De esta manera se asistió a un verdadero laissez-faire tecnológico (Nochteff 1995), que fue solo parcialmente revertido a partir de una re-configuración de la institucionalidad pública en CyT a partir del ańo 1996 (Piñero y Colombo 2001, 2002); esfuerzo que encontró en el marco de retracción del sector productivo la condición de imposibilidad para el despliegue de su potencialidad.

En forma sintética, las dinámicas más sobresalientes del derrotero productivo y tecnológico neoliberal argentino consistieron en:

- La desintegración del tejido productivo, vehiculizado por la contracción de los eslabones tecnológicamente más complejos (producción maquinaria y equipo e insumos industriales complejos) de su estructura, comportando la virtual desaparición de capitales productivos orientados principalmente al mercado interno y cuyas actividades reportaban requerimientos elevados de fuerza de trabajo y altas remuneraciones ${ }^{14}$.

- Una fuerte expulsión de trabajadores del ámbito fabril, determinando la constitución de un clásico ejercito industrial de reserva que forzó aún más la caída del valor de la fuerza de trabajo y un aumento de la tasa de explotación sectorial a través de los mecanismos de apropiación de plusvalía absoluta (precarización laboral, incremento de la extensión e intensidad de la jornada laboral y reducciones salariales ${ }^{15}$ ); y en menor

13 La reducción de los coeficientes de industrialización en países del capitalismo avanzado en las últimas décadas es de una naturaleza diferente a la argentina. Ello responde a las crecientes prácticas de deslocalización internacional de los procesos productivos y tercerización de numerosos servicios industriales por parte de los capitales industriales más concentrados, con contrapartida en un reforzamiento del control de aquellos eslabones de la cadena de valor intensivos en conocimiento y desarrollo tecnológico.

14 La participación de la producción de maquinaria y equipo en el valor agregado industrial cayó del 31\% al 17\% entre 1974 y 2003 (Herrera y Tavosnanska 2011).

15 Eliminada la posibilidad de realizar ajustes por las vías inflacionaria o devaluatoria, 
medida a través de aumentos en la productividad por modernización técnica ${ }^{16}$.

- La consolidación de una matriz distributiva fuertemente regresiva ${ }^{17}$.

- La concentración económica y centralización del capital en manos de firmas nacionales y extranjeras diversificadas que refuerzan su posicionamiento estructural en la dinámica fabril en base a su inserción en sectores basados en ventajas comparativas naturales.

- La extranjerización del aparato productivo vía arribo masivo de inversión extranjera directa (IED) con origen en los países desarrollados. El dato más sobresaliente de esta nueva oleada de avanzada del capital extranjero en el tejido productivo doméstico estriba en su escaso impacto en términos de ampliación de las capacidades productivas existentes, debido a que su arribo se produjo principalmente a partir de operaciones de adquisiciones de activos productivos ya existentes en el país ${ }^{18}$.

derivado ello de la adopción del patrón monetario de convertibilidad fija, la reducción de los costos salariales se vehiculizó a partir de 1994, en un contexto de abierto ensanchamiento de las filas del ejército industrial de reserva, a través de reducciones nominales de los salarios industriales. Entre 1994 y 1999 el salario industrial promedio registró una reducción cercana al 4\% (Azpiazu, Basualdo y Schorr 2001).

16 Según cálculos de Azpiazu, Basualdo y Schorr (2001) entre 1993 y 1999 la cantidad de obreros ocupados en la industria disminuyó en torno a un $4 \%$ anual promedio mientras que la productividad por obrero se expandió en un $6 \%$ anual promedio, lo cual es indicativo de la mayor tasa de explotación de la fuerza trabajo.

17 La participación de los salarios en el PIB se redujo un 17\% con la irrupción en 1976 de la última dictadura posicionándose por debajo del 30\% luego de haber alcanzado su máximo histórico en 1974 cercana al 50\%. En la década de 1990, luego de haber logrado una recuperación en los primeros años que permitió alcanzar valores cercanos al 45\%, desde la crisis mexicana de 1994 la participación se contrae a valores en torno al 37\% para desplomarse con la devaluación de 2002 por debajo del 30\% (Lindenboim, Kennedy y Grańa 2011).

18 El proceso de extranjerización avanzó en los años finales de la convertibilidad sobre los activos productivos de las fracciones más concentradas del capital nacional, quienes primero enajenaron a manos de empresas transnacionales sus participaciones en las empresas públicas privatizadas en la primera mitad de la década, y luego también activos en sus ámbitos tradicionales de acumulación fabril, manifestándose todo ello en un creciente protagonismo del capital transnacional en la cúpula empresarial del país. Ese proceso de avanzada del control del capital extranjero sobre el tejido productivo nacional, es además una de las variables determinantes de la ruptura de la comunidad de negocios de la convertibilidad (Basualdo 2006). Para una aproximación en detalle al proceso de extranjerización de la economía argentina 
- La primarización y simplificación productiva asociada a preeminencia de actividades agroindustriales y de procesamiento de materias primas (alimentos y bebidas, siderurgia, química y petroquímica) en manos de capitales con un ciclo de reproducción crecientemente internacionalizado para quienes el valor de la fuerza de trabajo no constituye factor de demanda.

Bajo el influjo de esas condiciones, se desarrolló una marcada prescindibilidad de las estructuras de ciencia y tecnología y de los instrumentos de política estatal tendientes a su fortalecimiento. Las políticas científicas se mantuvieron en un plano secundario de las prioridades del Estado y de la elite económica volcada a opciones blandas de acumulación (valorización financiera e industria basada en ventajas comparativas naturales) (Nochteff 1995). La industria que emerge y se consolida durante el neoliberalismo es, utilizando terminología de Hugo Nochteff la de un conjunto de invernaderos enclave, actividades de escala intensiva, con tecnologías maduras a escala internacional (siderurgia básica, química básica y petroquímica, automotriz) en detrimento de aquellas que requieren el uso de fuerza de trabajo de mayor calificación, intensivas en ciencia y tecnología, poseedoras de un mayor potencial articulador del tejido productivo en el espacio nacional.

En resumidas cuentas, el derrotero productivo y tecnológico neoliberal consolidado durante la década de vigencia del régimen de convertibilidad soslayó en sus propios términos la configuración de todo tipo de articulación entre un patrón de desarrollo económico volcado a la valorización no productiva del capital y a la explotación de ventajas naturales, y una estructura científico tecnológica, que en correspondencia a la retracción generalizada del estado, se encontró, en el mejor de los $\operatorname{casos}^{19}$, desatendida por las políticas públicas. Se propone a continuación el esbozo de las principales transformaciones en términos del desempeño económico-productivo desde la crisis del capitalismo neoliberal en 20012002, a los fines de poner en evidencia la existencia de nuevas condiciones macroeconómicas para la revalorización de la política científico-tecnológica.

desde la emergencia de la convertibilidad pueden consultarse los siguientes trabajos: Burachik (2009), Wainer (2011), Manzanelli y Schorr (2012), Gaggero (2012).

19 Resulta paradigmático de esta situación el llamado a la comunidad científica argentina a lavar los platos del entonces ministro de economía Domingo Felipe Cavallo. 


\section{EL NUEVO ESCENARIO POST CRISIS NEOLIBERAL}

La Ley de Emergencia Pública y Reforma del Régimen Cambiario de enero de 2002, sucedida por la devaluación de la moneda nacional, formalizaron el fin del régimen de convertibilidad, sentando así las bases para el surgimiento de un nuevo esquema de crecimiento económico, que sobre la base de un tipo de cambio competitivo desplaza el eje de la acumulación desde la valorización financiera hacia la actividad productiva.

La recomposición de las condiciones para la acumulación del capital a la salida de la crisis encontraron sustento en una masiva desposesión de la clase que vive del trabajo a favor del conjunto del capital, y principalmente a sus fracciones más concentradas, motorizada por la devaluación del peso argentino durante 2002. La modificación cambiaria conllevó una caída del $30 \%$ del salario real y del 35\% de los costos salariales (EPH-INDEC), catapultando la tasa de ganancia del capital sobre una reducción de diez puntos porcentuales de la participación de los salarios en el producto, pasando del 42,1\% en 2001 al 31,4\% en 2002 (CIFRA 2011).

Esta recomposición de la tasa de ganancia del capital posibilitó así el transitó desde la crisis más aguda de su historia nacional al período de crecimiento más acelerado registrado. Desde la devaluación de 2002 hasta 2012, el PBI experimentó un crecimiento a una tasa acumulativa promedio del 7,2\% anual, superando a partir de 2005 los niveles anteriores al inicio de la crisis de la convertibilidad, promediando en el período 2003-2012 un desempeño un 28\% superior al registrado en 1998 (mejor dato de la década de 1990) y 50\% superior al de 2002. (Gráfico 1).

Al tiempo que configuró un marco más favorable para la acumulación de capital, la devaluación dio lugar a un nuevo esquema de precios y rentabilidades relativas, que trastocó el esquema de ganadores y perdedores en el seno de las diferentes fracciones del capital sobre el cual se había sostenido el régimen de convertibilidad. La evolución de los precios relativos de las distintas actividades económicas y de la tasa de interés desde 2002, posibilitó un escenario macroeconómico de crecimiento basado en la producción nacional de mercancías transables en detrimento del sector financiero y de los servicios. La tasa de interés real experimentó una fuerte caída, siendo incluso negativa en la mayor parte del período posconvertibilidad, incentivando así la inversión productiva y desestimando la valorización en el mercado financiero local. En paralelo, los precios de los servicios se encontraron en promedio un $16 \%$ por debajo de la evolución de los precios del conjunto de la economía, situación que favoreció la reducción de costos y mejoró la competitividad del sector 
productor de bienes transables ${ }^{20}$. Como consecuencia, las actividades con mayor capacidad para captar excedente por efecto tipo de cambio alto y caída del costo salarial en moneda internacional, son aquellas dedicadas a la producción de bienes transables, y aquellas con sesgo a la utilización intensiva en trabajo vivo ${ }^{21}$. Todo ello en franco contraste con las transferencias de excedente hacia el sector financiero y los servicios en el escenario de sobrevaluación monetaria en la década de 1990.

\section{El reimpulso de la industria local}

La actividad fabril respondió favorablemente al estímulo macroeconómico derivado de la devaluación monetaria. El dólar alto proporcionó a la industria local un nuevo margen de protección frente a las importaciones y un ajuste de los costos salariales ${ }^{22}$, lo cual sumado a la reimposición de las retenciones a las exportaciones agropecuarias ${ }^{23}$, indujeron una mejora en la condiciones de competitividad de la industria que opera en el espacio nacional. Con ello el sector manufacturero registró las tasas de expansión más elevadas de la historia del país, a un promedio del 7,7\% anual acumulativo entre 2003 y 2012; siendo éste un 1,5\% más elevado que el promedio de los servicios, un $0,5 \%$ superior que la producción de bienes y un $0,5 \%$ por encima al promedio del conjunto de la economía, constituyendo, por lo tanto, el sector un importante factor de tracción del desempeño económico agregado.

La expansión industrial se desarrolló en momentos inmediatamente posteriores a la devaluación, sobre la puesta en funcionamiento de capacidades ociosas acumuladas en la década previa, la cual en 2002 rondaba

20 En ello tuvo un efecto fundamental la desindexación a la inflación norteamericana y el congelamiento de las tarifas de servicios público en 2002.

21 El cálculo de precios relativos en base a información del INDEC permite concluir que los precios del sector agropecuario entre 2002 y 2011 crecieron en promedio un $71 \%$ por encima de los del conjunto de la economía; los precios de la minería un $190 \%$ y los industriales un $25 \%$.

22 La caída del costo salarial disparó la tasa de ganancia desde un promedio del 24,8\% al 37,2\% entre 2002 y 2010 (Manzanelli 2012).

23 El establecimiento de retenciones a las exportaciones primarias permite desacoplar el precio de los bienes salarios respecto al precio internacional de las materias primas que forman parte de la canasta de consumo de los trabajadores, abaratando en consecuencia el costo laboral, a su vez que reduce costes de aprovisionamiento de insumos básicos al sector industrial. 
el $50 \%$ en la mayor parte de los ramos (UCI-INDEC). Posteriormente, con su agotamiento se desarrolló una ampliación de las capacidades productivas con asiento en una recuperación de la inversión en capital fijo, que a partir de 2005 se ubicó en torno al $20 \%$ del $\mathrm{PBI}^{24}$.

\section{Gráfico 1: Evolución del PBI y PBI industrial, 1993-2011 (índice base $1993=100$ y porcentajes)}

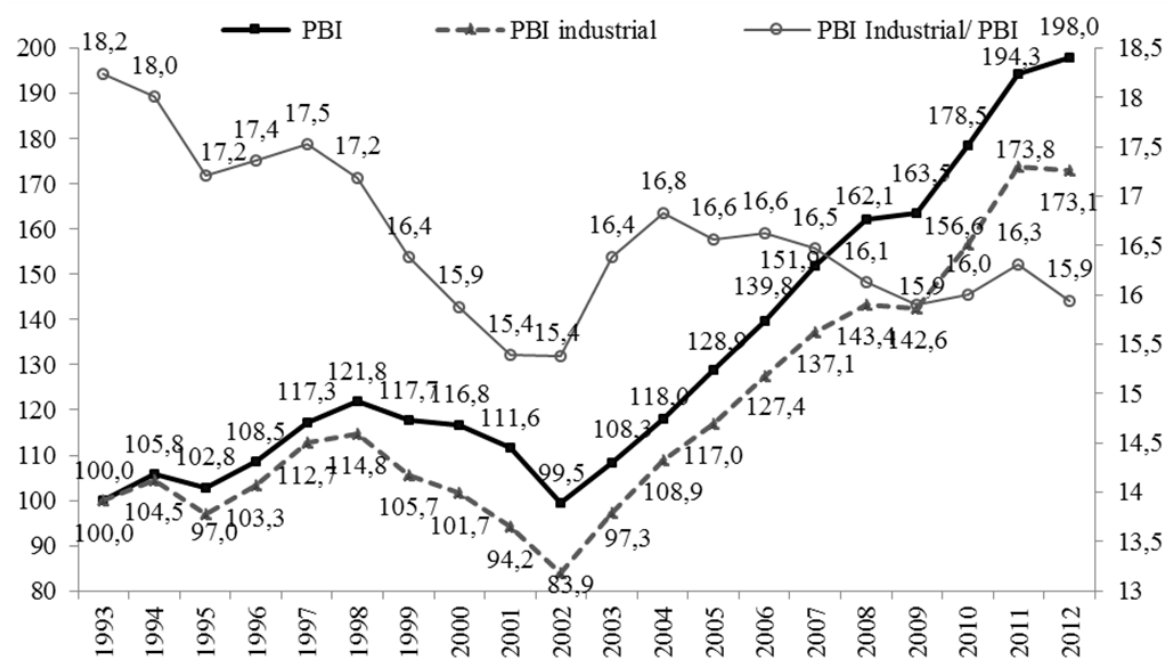

Fuente: Elaboración propia en base a información del INDEC.

La etapa de la posconvertibilidad reconoció así la reversión de una de las tendencias regresivas más caras al modelo financiero y de ajuste estructural (Schorr 2005), a saber: la sistemática pérdida de gravitación fabril en la dinámica del crecimiento económico nacional. Tal como se observa en el Gráfico 1, en los años comprendidos entre 2003 y 2011 mientras el PBI global creció un $95,4 \%$ el fabril lo hizo un 107,2\%; produciéndose así un incremento en el coeficiente de industrialización del 15,4\% al 16,3\%. Desde 2005 el PBI industrial supera todos los registros de la década de

24 Pese a ello, la tasa de acumulación fue limitada en tanto la inversión reproductiva (equipo y maquinaria durable) representó en promedio solo alrededor el $40 \%$ del total de la IBIF; mientras que la construcción, dentro de la cual la residencial es predominante, fue en promedio el restante 60\%. Estas limitaciones del proceso inversor tienen principal asiento según Azpiazu, Schorr y Manzanelli (2012), en la reticencia del capital concentrado a aumentar la tasa de acumulación en la posconvertibilidad; fenómeno vinculado a una acumulación de capacidad por encima del promedio en los años de crisis, que a la vez les habría permitido consolidar su posición oligopólica a través del establecimiento de fuertes barreras de entrada. 
1990, pero observándose también a partir de allí una ralentización de su expansión en relación al producto global que se ve acentuada desde 2007, revirtiéndose durante los años 2010 y 2011 aún sin recuperar sus niveles de 2004, año en que alcanzó el máximo de la década con un 16,8\% del agregado. Como se observa en el Gráfico 2 durante 2012 se registró una fuerte caída del desempeño industrial en relación al agregado, mientras el PBI se expandió en ese año un 3,7\% el PBI industrial se contrajo un 0,7\%, perdiendo el sector casi medio punto porcentual de participación en el agregado (del 16,3\% al 15,9\%) 25 .

El mayor poder de negociación de la clase trabajadora en un contexto expansivo combinado con la implementación de políticas de gasto social ${ }^{26}$, habilitaron progresivamente la reversión de la brecha distributiva dramáticamente abierta por la crisis de 1998-2001 y más aún por el quiebre devaluatorio de 2002. La creación de más de 4.000.000 de puestos de trabajo, redujo la tasa de desempleo desde un $21,7 \%$ registrado en el primer trimestre de 2003, al 7,1\% en el primer trimestre de 2012, el salario real promedio alcanzó hacia 2007 los niveles de $2001^{27}$, la porción del producto apropiada por los trabajadores recuperó lentamente su piso anterior a la devaluación de 2002 en torno al 40\% (CIFRA 2011); y el índice de Gini pasó de 0,534 a $0,433^{28}$ entre el primer trimestre de 2003 y el primer trimestre de 2012. (EPH-INDEC, CIFRA 2011, Lindenboim y Graña 2011) ${ }^{29}$.

25 Una evaluación respecto del carácter coyuntural o no de ese último registro solo puede ponderarse a partir de proyecciones futuras respecto al desempeńo del sector, excediendo ello los alcances de este trabajo.

26 Solo a título de ejemplo, entre estas medidas vale mencionar los incrementos salariales implementados por Decreto Presidencial, la reapertura de las paritarias, los aumentos sistemáticos de las jubilaciones y pensiones mínimas, el establecimiento de la Asignación Universal por Hijo (AUH).

27 Pese a ello, el costo salarial en 2010 se mantenía un 25\% por debajo del nivel de 2001 y un $34,1 \%$ por debajo del de 1993 , por lo cual los incrementos salariales obtenidos en los últimos años, están muy lejos de significar un estrangulamiento de las ganancias (CENDA 2007, Manzanelli 2012).

28 Según ingreso per cápita.

29 Pese a las mejoras descriptas, los estudios destacan dos cuestiones que las matizan. La primera es la continuidad de altos niveles de trabajo no registrado (35\%) y de precariedad de la fuerza de trabajo (50\%). En segundo lugar, se observa, a partir de 2007, una ralentización en la mejora de los índices de distribución del ingreso. Así, luego de haberse necesitado varios años de niveles inéditos de crecimiento 
El sector manufacturero ha desempeñado un rol central en la expansión de los niveles de empleo, y por ende en la mejora global de los indicadores sociales y distributivos. En contraste con las características de la dinámica económica y su relación con las condiciones de creación de empleo dominantes durante la década de la convertibilidad, la década transcurrida desde la devaluación se ha caracterizado por una mayor elasticidad de la relación entre crecimiento del producto y el número de puestos de trabajo creados, respondiendo así al nuevo sesgo trabajo intensivo del esquema de precios relativos ${ }^{30}$.

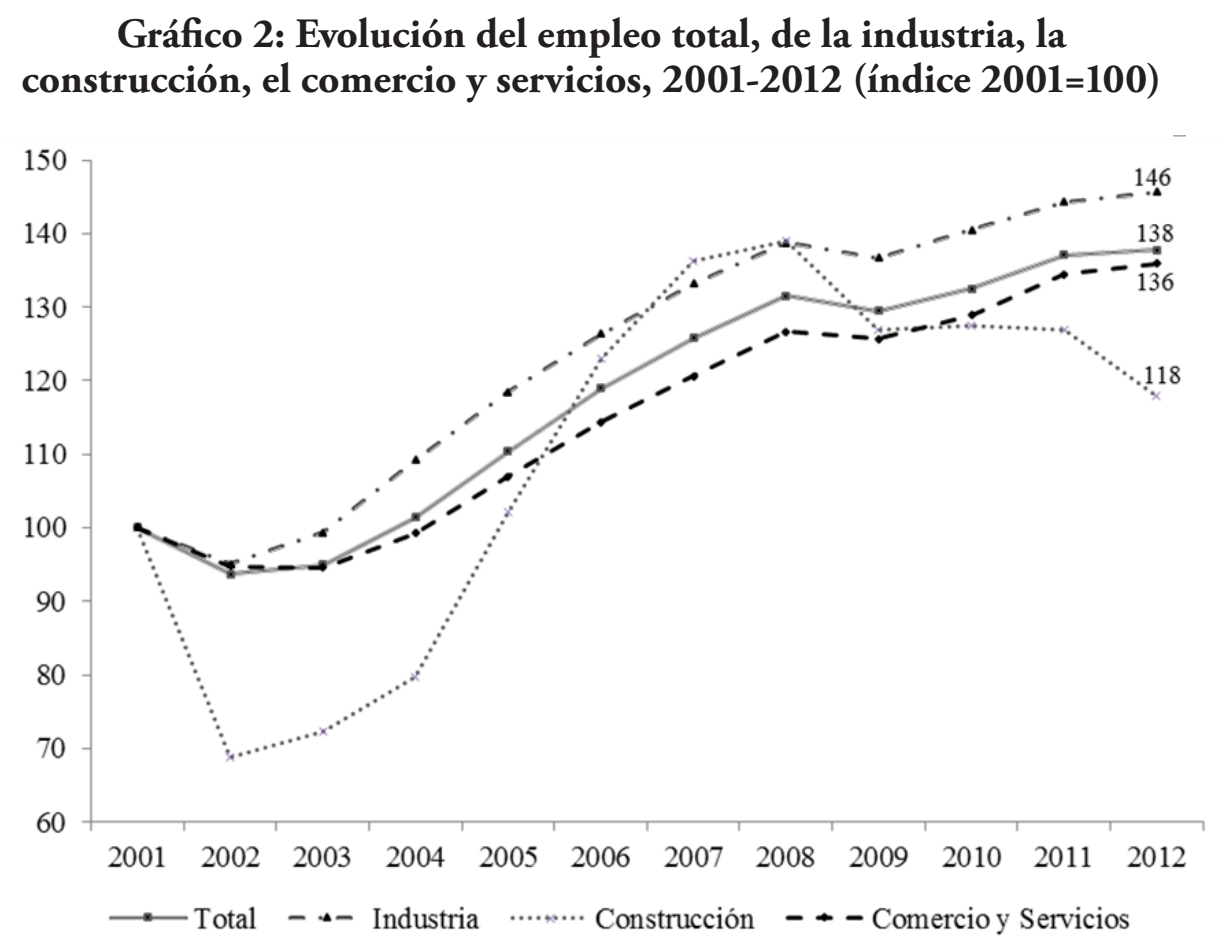

Fuente: Elaboración propia en base a información del INDEC.

ininterrumpido para recuperar posiciones distributivas anteriores a la devaluación de 2002, los distintos indicadores se han estabilizado en los niveles vigentes durante la década de 1990, estando aún muy lejanos de los mejores registros de años de industrialización sustitutiva.

30 Durante la década de vigencia del régimen de convertibilidad un punto de crecimiento del producto generaba en promedio una expansión del empleo del $0,35 \%$, en el período 2002-2007 la relación ascendió al 0,62\% (Gonzáles 2011). 
Mientras el empleo global se expandió entre 2001 y 2012 un 38\%, el generado por la industria lo hizo un $46 \%$, siendo ello un $10 \%$ superior a la expansión del empleo generada por el comercio y servicios $(36 \%$ en ese período). Mención especial merece la gravitación de la actividad de la construcción en las tasas de absorción de fuerza de trabajo, aunque como se observa en el Gráfico 2, el sector se muestra mucho más sensible a los momentos contractivos o de expansión del desempeño económico general que manifiesto por la industria manufacturera. Así por ejemplo, mientras el empleo en 2005 creció un $8,9 \%$ la construcción lo hizo en un $28,2 \%$ y el generado por la manufactura un $8,4 \%$, sin embargo en 2009 cuando el empleo agregado se contrajo un 1,6\%, la expulsión de fuerza de trabajo en la construcción fue del 8,7\% y en la industria del 1,5\%.

\section{Transformaciones e invariantes del perfil de crecimiento industrial}

Al amparo de la protección del tipo de cambio y la progresiva recuperación del mercado interno, la expansión fabril ha involucrado al conjunto de las ramas, siendo uno de los datos más significativos la reaparición y reimpulso de actividades intensivas en conocimiento, fuertemente agredidas por el programa neoliberal de la década anterior ${ }^{31}$. Las pequeñas y medianas empresas (PYMEs) protagonizaron un papel sustancial en la recuperación del producto industrial, explicando aproximadamente el $40 \%$ del valor bruto de producción y un $70 \%$ de la expansión de la ocupación fabril (Porta y Fernández Bugna 2011). Desde el punto de vista cualitativo, el crecimiento de estos pequeńos capitales constituye un dato en manifiesto contraste con lo acontecido durante la década de sobrevaluación cambiaria, en tanto se encuentran generalmente insertos en actividades que reportan mayores requerimientos de mano de obra calificada que las que involucran los capitales más concentrados, generalmente abocadas a actividades asociadas a la explotación de ventajas naturales ${ }^{32}$.

Pese a lo arriba enunciado, la recuperación de la industria como fuente principal de tracción del crecimiento económico en la última década, no ha modificado en lo sustancial el perfil de especialización sectorial fuertemente asociado al procesamiento de materias primas consolidado en la década de 1990, habiéndose incrementado la gravitación de las firmas

31 Entre 2003 y 2010, los casos más ilustrativos de crecimiento de ramas tecnológicamente complejas han sido maquinaria y equipo, con un $7 \%$ promedio anual, instrumentos médicos y equipos de precisión, con un $6,6 \%$ promedio anual, y maquinaria y equipos de transporte, con un $3,2 \%$ promedio anual.

32 En ese sentido, el desarrollo de las industrias del software constituye un caso destacado sobre el cual se profundizará en un apartado posterior. 
concentradas exportadoras ${ }^{33}$. Así, entre 2001 y 2010, cinco divisiones industriales dedicadas a las primeras etapas del procesamiento de materias primas y producción de bienes intermedios commoditizados -en las que grandes grupos nacionales y extranjeros que se expandieron bajo hegemonía neoliberal tienen posiciones dominantes-, pasaron a explicar del $65,9 \%$ al $67,1 \%$ del PBI industrial en ese último año. Elaboración de productos alimenticios y bebidas el 32,3\%, sustancias y productos químicos $12,1 \%$, vehículos y automotores ${ }^{34} 11,1 \%$, refinación de petróleo $6,1 \%$ y fabricación de metales comunes 5,5\%.

A lo anterior se le suma desde 2007, producto de un proceso inflacionario en torno a tasas cercanas al $20 \%$ anual, una desaceleración del ritmo de crecimiento de ramas de mayor complejidad tecnológica cuya posición competitiva en los primeros años de la posconvertibilidad mejoró al amparo de la nueva posición cambiaria ${ }^{35}$.

\section{Gráfico 3: Tasas promedio de crecimiento de la producción, ramas seleccionadas, períodos 2003-2007 y 2007-2011}

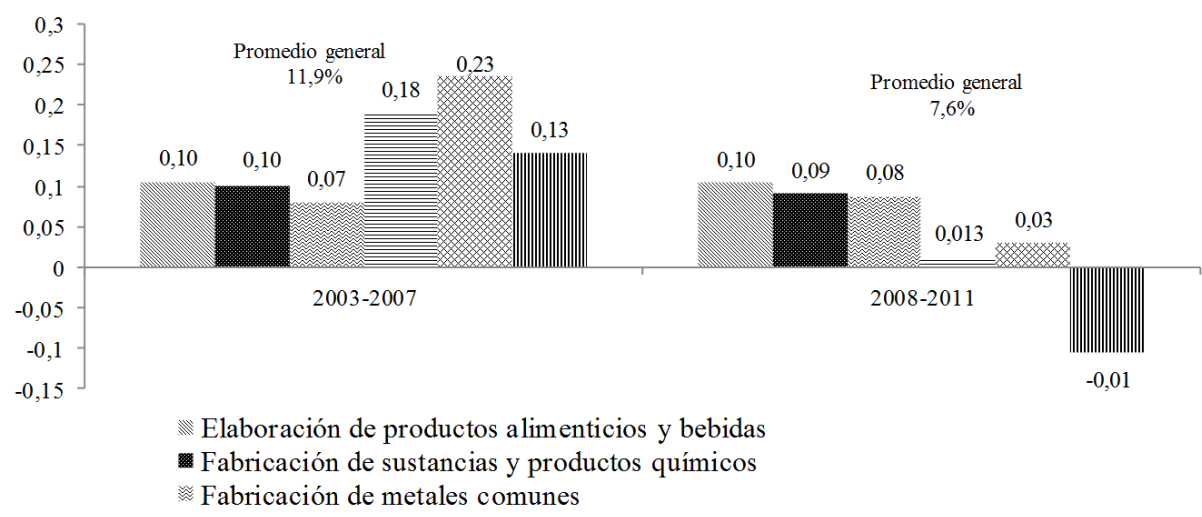

Fuente: Elaboración propia en base a información del INDEC.

33 Las doscientas firmas industriales de mayor facturación en el país pasaron de explicar entre el 18\% y 22\% del valor bruto de producción total entre 1993 y 1997 al 24-25\% entre 1998 y 2001; catapultándose en la posconvertibilidad (entre 2003 y 2008) en torno al 31-33\% (Azpiazu y Manzanelli 2011).

34 Siendo la producción automotriz la única división que no está asociada a la explotación de ventajas naturales, se trata de una actividad en la que predomina el ensamblado de componentes importados.

35 Según estimaciones de CIFRA-CTA, el tipo de cambio real multilateral, acumula entre 2007 y 2011 una apreciación aproximada del 20\%, encontrándose en la actualidad apenas por encima los niveles de 2001. 
Como se desprende del Gráfico 3, en el período 2003-2007 las ramas de mayor complejidad tecnológica (en el ejemplo, maquinaria y equipo, instrumentos médicos, ópticos y de precisión y equipos de transporte) experimentaron tasas de crecimiento de sus volúmenes físicos de producción superiores a los del conjunto de la industria. Pero esa situación se revierte a partir de 2008, reportando un dinamismo inferior al experimentado por el promedio sectorial, mientras que ramas manufactureras tecnológicamente menos dinámicas y con competitividad basada en el uso intensivo de recursos naturales o con patrones tecnológicos internacionalmente estandarizados, que se modernizaron en base a reemplazar capacidad local por la incorporación de insumos y maquinaria importada durante la convertibilidad (en el ejemplo: alimentos y bebidas, metales comunes y química), han recobrado su centralidad en la dinámica sectorial. Esa modificación del perfil de crecimiento de la industria resulta al mismo tiempo un importante factor explicativo de la desaceleración de las tasas de absorción sectorial de fuerza de trabajo, y en general del estancamiento de los indicadores sociales y distributivos que no logran romper el techo neoliberal (Gonzáles 2011).

Un plano adicional de consideraciones respecto a la performance tecnológico-productiva de la industria argentina en la posconvertibilidad se ubica en referencia a los intercambios comerciales externos. La combinación de políticas de apertura y liberalización en un marco de sobrevaluación cambiaria habilitaron en la década de 1990 el arribo masivo de mercancías industriales desde el exterior. El recrudecimiento de la situación competitiva redundó en la desaparición de numerosos entramados productivos, $\mathrm{y}$ muy especialmente de aquellos cuyas condiciones de competitividad no anclan ventajas naturales, siendo reemplazados por insumos y maquinarias importadas, todo lo cual dio como resultado el reforzamiento de una matriz industrial con un alto grado de dependencia tecnológica ${ }^{36}$.

Desde la ruptura de la convertibilidad, como se observa en la Tabla 1, el sector manufacturero ha desarrollado una incremento de sus exportaciones, que liderado por las manufacturas de origen industrial (MOI), ha dado lugar - por primera vez desde la década de 1980-a la existencia de situación de superávit comercial sectorial ${ }^{37}$. Ahora bien, vale preguntarse si ese dato

36 Según Ortiz y Schorr (2009), la participación de los ramos productores de bienes de capital en el PBI industrial se contrajo del 5,6\% al 3,7\% entre 1993 y 2002, recuperándose parcialmente al 5,3\% hacia 2007.

37 Sin embargo existe una diferencia sustancial entre ambos períodos de superávit comercial industrial. Mientras que en la década de 1990 ocurrió en un escenario de fuerte contracción sectorial, en la posconvertibilidad fue el corolario de una fuerte expansión del producto industrial. 
es significativo de la recomposición de casilleros de la matriz productiva, fundamentalmente de aquellas industrias complejas, agredidas por el proceso de reestructuración regresiva. Como se observa en la Tabla 1, el superávit comercial industrial en la posconvertibilidad se extendió desde 2002 a 2006 pero exhibiendo un progresivo deterioro a lo largo del período. Con la recuperación del mercado interno luego de la crisis se expandieron un conjunto de industrias de bienes de uso abocadas a abastecerlo, con ello se incrementaron las necesidades de bienes de producción (maquinaria y equipo e insumos industriales intermedios) que ante la ausencia de una industria local capaz de abastecerla, condujeron a un acelerado incremento de las importaciones industriales.

Mientras las exportaciones industriales se incrementaron en el período 2002-2011 a una tasa promedio anual del 15\%, las importaciones lo hicieron a una tasa del $30 \%$ anual promedio, redundando ello lógicamente a partir de 2007 en la reaparición del déficit comercial sectorial, situación progresivamente agravada hasta alcanzar en 2011 la cifra de US\$ 7.318.000.000.

\section{Tablal: Evolución de las exportaciones, importaciones y del saldo comercial del sector industrial, 1993-2010}

\begin{tabular}{cccc} 
Años & Exportaciones & Importaciones & Saldo \\
\hline 1993 & 9.711 & 16.104 & -6.393 \\
1994 & 11.360 & 20.772 & -9.412 \\
1995 & 15.037 & 19.097 & -4.060 \\
1996 & 16.245 & 22.483 & -6.238 \\
1997 & 18.868 & 28.643 & -9.774 \\
1998 & 18.601 & 29.795 & -11.194 \\
1999 & 16.608 & 24.227 & -7.618 \\
2000 & 17.993 & 23.730 & -5.738 \\
2001 & 17.906 & 19.064 & -1.159 \\
2002 & 17.843 & 8.184 & 9.659 \\
2003 & 20.933 & 12.822 & 8.111 \\
2004 & 24.902 & 20.871 & 4.031 \\
2005 & 28.840 & 26.666 & 2.174 \\
2006 & 34.571 & 31.944 & 2.627 \\
2007 & 41.103 & 41.788 & -686 \\
2008 & 50.787 & 52.932 & -2.145 \\
2009 & 42.742 & 36.312 & 6.430 \\
2010 & 49.614 & 52.835 & -3.221 \\
2011 & 60.289 & 67.607 & -7.318
\end{tabular}

Fuente: Elaboración propia en base a información del CEP.

La composición por ramas de los saldos comerciales permite dar cuenta del mantenimiento de una marcada heterogeneidad estructural al interior de la matriz productiva. En 2011 ramas asociadas a las primeras etapas del 
procesamiento de recursos naturales y de escaso dinamismo tecnológico como alimentos y bebidas, metales comunes y manufacturas del cuero, fueron las únicas en operar con superávit comercial, mientras que a medida que se avanza en los eslabones más complejos de la matriz productiva, los déficit se vuelven más agudos, siendo el caso más significativo el de maquinaria y equipo por US\$ 6.132.000.000.

Al mismo tiempo, la Tabla 2 permite corroborar la existencia de ramas de mediano y alto contenido tecnológico con capacidad exportadora (maquinaria y equipo, equipo de transporte, instrumentos médicos, entre otras). Ello revela la recomposición de segmentos complejos del entramado productivo que permitieron una diversificación de la canasta exportadora en la posconvertibilidad. Pero la mayor significación de los montos importados en esos mismos rubros pone de manifiesto la existencia de desarticulaciones en las cadenas de valor y desbalances competitivos en el seno de esas ramas de la industria. 


\section{Tabla 2: Exportaciones, importaciones y saldo comercial de ramas seleccionadas, 2011}

\begin{tabular}{|c|c|c|c|}
\hline Ramas & & Importaciones & Saldo \\
\hline Alimentos y bebidas & $27.008,8$ & $1.314,1$ & $25.694,68$ \\
\hline Productos de tabaco & 21,1 & 58,8 & $-37,76$ \\
\hline Productos textiles & 442,2 & $1.221,0$ & $-778,81$ \\
\hline $\begin{array}{l}\text { Confección de prendas de vestir, terminación y } \\
\text { teñido de pieles }\end{array}$ & 137,0 & 434,4 & $-297,43$ \\
\hline $\begin{array}{l}\text { Curtido y terminación de cueros, fabricación } \\
\text { de productos de cuero }\end{array}$ & 978,3 & 686,2 & 292,12 \\
\hline $\begin{array}{l}\text { Producción de madera y fabricación de } \\
\text { productos de madera y corcho }\end{array}$ & 211,2 & 223,5 & $-12,27$ \\
\hline Papel y productos de papel & 651,8 & $1.309,1$ & $-657,33$ \\
\hline $\begin{array}{l}\text { Edición e impresión, reproducción de } \\
\text { grabaciones }\end{array}$ & 82,1 & 199,3 & $-117,22$ \\
\hline $\begin{array}{l}\text { Fabricación de coque, producto de la } \\
\text { refinación del petróleo }\end{array}$ & $2.520,0$ & $5.605,6$ & $-3.085,54$ \\
\hline Sustancias y productos químicos & $7.487,7$ & $12.518,4$ & $-5.030,73$ \\
\hline Productos de caucho y plástico & 937,0 & $2.337,4$ & $-1.400,41$ \\
\hline Productos minerales no metálicos & 272,2 & 686,2 & $-414,04$ \\
\hline Metales comunes & $5.348,2$ & $3.056,3$ & $2.291,88$ \\
\hline Metal, excepto maquinaria y equipo & 459,3 & $1.627,5$ & $-1.168,25$ \\
\hline Maquinaria y equipo NCP & $1.646,9$ & $7.778,9$ & $-6.131,93$ \\
\hline $\begin{array}{c}\text { Maquinaria de oficina, contabilidad e } \\
\text { informática }\end{array}$ & 29,0 & $2.029,8$ & $-2.000,78$ \\
\hline Maquinaria y aparatos eléctricos NCP & 448,6 & $3.502,6$ & $-3.054,06$ \\
\hline $\begin{array}{l}\text { Equipos y aparatos de radio, televisión y } \\
\text { comunicaciones }\end{array}$ & 61,9 & $4.382,2$ & $-4.320,35$ \\
\hline Instrumentos médicos y de precisión & 223,7 & $1.758,2$ & $-1.534,55$ \\
\hline $\begin{array}{l}\text { Vehículos automotores, remolque y } \\
\text { semirremolques }\end{array}$ & $10.219,6$ & $13.700,3$ & $-3.480,66$ \\
\hline Equipo de transporte NCP & 979,0 & $2.048,1$ & $-1.069,06$ \\
\hline $\begin{array}{l}\text { De muebles y colchones, industrias } \\
\text { manufactureras NCP }\end{array}$ & 123,4 & $1.128,6$ & $-1.005,22$ \\
\hline
\end{tabular}

El desempeño deficitario del comercio exterior sectorial en los últimos años, sobre todo importante por la composición importada de la inversión en maquinaria y equipo durable ${ }^{38}$, da cuenta de las limitaciones con que se ha topado el proceso sustitutivo de importaciones, poniendo en cuestión la posibilidad de continuidad de un crecimiento industrial que con altos requerimientos de divisas para afrontar las importaciones de insumos y

38 En 2010 las importaciones significaron el 67\% de la formación de capital en equipo durable (INDEC). 
maquinaria, abre las puertas a los viejos problemas de restricción externa y ciclos de stop and go que dominaron la dinámica sectorial a mediados del siglo pasado. Sobre ello se vuelve pertinente una intervención de política estatal en materia tecnológica, tendiente a la promoción de actividades estratégicas en términos de sus requerimientos de fuerza de trabajo con alto nivel de calificación, sus capacidades para promover sinergias al interior del entramado productivo y su potencial frente al objetivo de alivianar los requerimientos de moneda divisa del sector manufacturero.

Habiéndose hasta aquí presentado un panorama general de las principales transformaciones e invariantes del desempeño productivo de la posconvertivilidad, se tratarán en lo sucesivo las sustanciales novedades que la crisis del neoliberalismo ha traído en términos de la posición y capacidades estatales en materia de política científica y tecnológica. Reconociéndose a partir de 2002 la recuperación de la producción como núcleo dinámico del desarrollo como un escenario favorable para el despliegue de una promisoria política científica, se vuelve pertinente insistir sobre las potencialidades que ella contiene para la reversión de las herencias más caras del derrotero productivo neoliberal.

\section{LA TRANSFORMACIÓN PRODUCTIVA Y LA POLÍTICA CIENTÍFICA: RECONSTRUCCIÓN DE LAS CAPACIDADES EN CYT EN LA POSCONVERTIBILIDAD}

El modelo de desarrollo y el sostenido crecimiento económico de los últimos años ha devuelto el auge a las políticas de CyT, incorporando el tema de la promoción de la investigación y la innovación tecnológica como esquema que recupera a la industria y a la producción como ejes centrales del nuevo modelo de acumulación. Es así que las políticas de ciencia y tecnología en Argentina han venido cambiando de estilo y de enfoque, siguiendo las tendencias que prevalecen en la mayor parte de los países de América Latina (Albornoz 2009). El foco estuvo centrado en reconstruir las capacidades en $\mathrm{Cy} \mathrm{T}$ y fomentar los procesos de innovación y de transferencia de conocimientos.

En este periodo conceptos como sistema nacional de innovación y sociedad del conocimiento se han generalizado en base a los cuales se fueron elaborando nuevos marcos normativos para el diseño de las políticas. Como señala Albornoz (2009: 68),

[...] la revisión de los viejos modelos de política científica y de los diseños institucionales tradicionales se ha ido tornando necesaria para poder abordar objetivos vinculados con el impulso a la innovación como parte de nuevas estrategias de desarrollo a las que se suele agregar en forma cada vez más explícita el impulso a la equidad social. 
Como se explicitó en los apartados anteriores, las políticas científicas y tecnológicas de la década neoliberal se mantuvieron en un plano secundario de las prioridades del estado y de la elite económica y sus resultados exhibieron una tendencia hacia laissez-faire en materia tecnológica basada en las tradiciones neoclásicas, tanto en lo que hace al rol de las políticas públicas como en el tratamiento de la cuestión tecnológica (Chudnovsky y López 1996). La apertura de la economía y la adquisición de capital y tecnología como ejes estratégicos de la modernización tecnológica no permitieron el avance hacia un mayor desarrollo de capacidades científicotecnológicas locales. Por lo tanto, en este nuevo contexto, los esfuerzos del Estado a partir de 2003 estuvieron enfocados en recomponer un esquema de políticas de largo plazo, de carácter más sistémico y con una mejor definición de objetivos estratégicos y la búsqueda de una mayor integración y coordinación del sistema científico-tecnológico (MINCYT 2012).

Los objetivos centrales expresados en la política científica estuvieron enfocados en dos ejes:

- Aumentar la base científica y la capacidad tecnológica.

- Fortalecer la innovación, la modernización y la vinculación tecnológica en las actividades productivas.

En este marco, la evolución de la política científica y tecnológica pareció seguir una pauta que fue, desde el apoyo a la formación de capital humano y la jerarquización de las instituciones con incumbencia en ese campo, hacia el apuntalamiento de la innovación, apoyándose en los esfuerzos de los organismos públicos en CyT, pasando por una fase dirigida principalmente a apuntalar el desarrollo de ramas de la producción con tecnologías de punta. Es así, que se observan reformas institucionales como la creación del Ministerio de Ciencia, Tecnología e Innovación Productiva en el año 2007, y el diseño de nuevos instrumentos que buscan incentivar la innovación y fortalecer los vínculos entre los centros de investigación y la producción.

A diferencia de los países con alto desarrollo industrial, los que componen la región latinoamericana presentan mayores debilidades en su entramado productivo y en la relación entre éste y los centros de producción de conocimiento científico-tecnológico. Debido a ello, en países como Argentina, asume una mayor trascendencia el papel del Estado como promotor de las actividades científicas y tecnológicas y de las vinculaciones entre los diferentes componentes del sistema orientados hacia la innovación (Rozenwurcel y Bezchinsky 2007). 


\section{Algunos Resultados de LOS ESFUerzos en InVESTigación Y Desarrollo \\ Gasto en Investigación y Desarrollo}

Como se desarrolló en el apartado anterior, uno de los primeros objetivos de la política científica fue reconstruir las capacidades científicas tecnológicas centrada en los recursos humanos, es así que se destaca un aumento significativo del gasto del Estado en $\mathrm{I}+\mathrm{D}$ y la expansión y calificación de los recursos humanos en CyT. Dentro de la estructura científica tecnológica sobresale la presencia de una base de recursos humanos amplia y altamente calificada. En materia de gastos en investigación y desarrollo, el gobierno impulsó un sostenido crecimiento, pasando de representar el 0,41\% del PBI en el año 2003 al 0,62\% en el 2010 (RICYT 2010).

\section{Gráfico 4: Argentina, Gasto en Investigación y Desarrollo como proporción del PBI, 1996-2010}

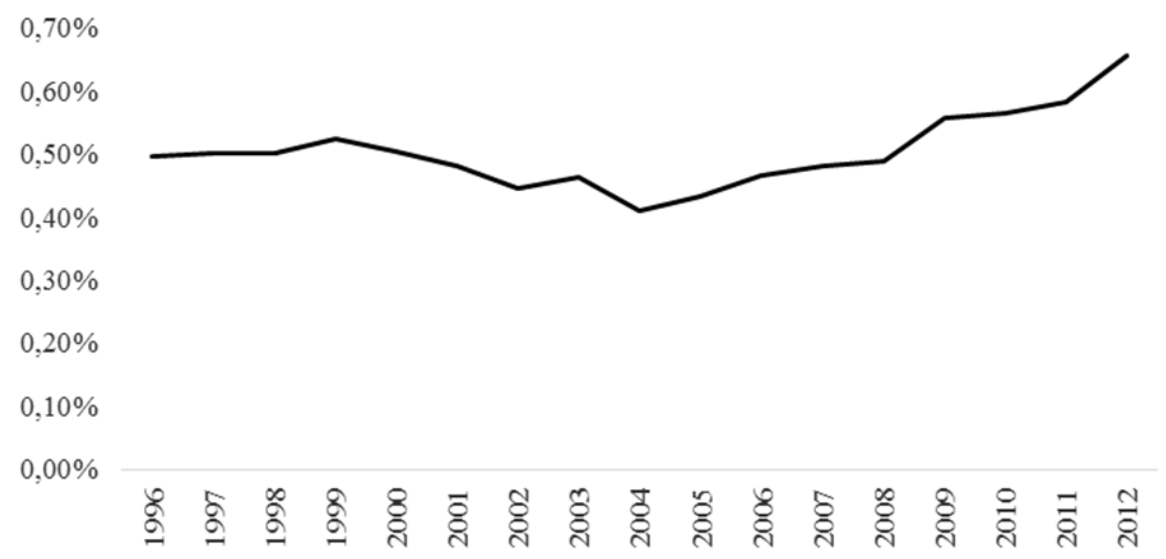

Fuente: Elaboración propia en base a RICYT (2015).

Formación de recursos humanos en ciencia, tecnología e innovación

En relación a la formación de recursos humanos, se destaca en este periodo la expansión y calificación de los recursos humanos. El apoyo a la formación de posgrado, y las estrategias de repatriación de científicos contribuyeron a consolidar para 2011 una base de 46.929 personas $^{39}$ dedicadas a tareas de investigación y desarrollo.

39 Investigadores, becarios, personal técnico de $\mathrm{I}+\mathrm{D}$ y personal de apoyo de $\mathrm{I}+\mathrm{D}$. 
Desde el año 2003 se produjo una fuerte expansión del número de investigadores y, en particular, de becarios de investigación, arribando en el 2011 a 32.962 y 13.967 , respectivamente.

\section{Gráfico 5: Cantidad de investigadores y becarios con dedicación exclusiva (más de 30 horas semanales)}

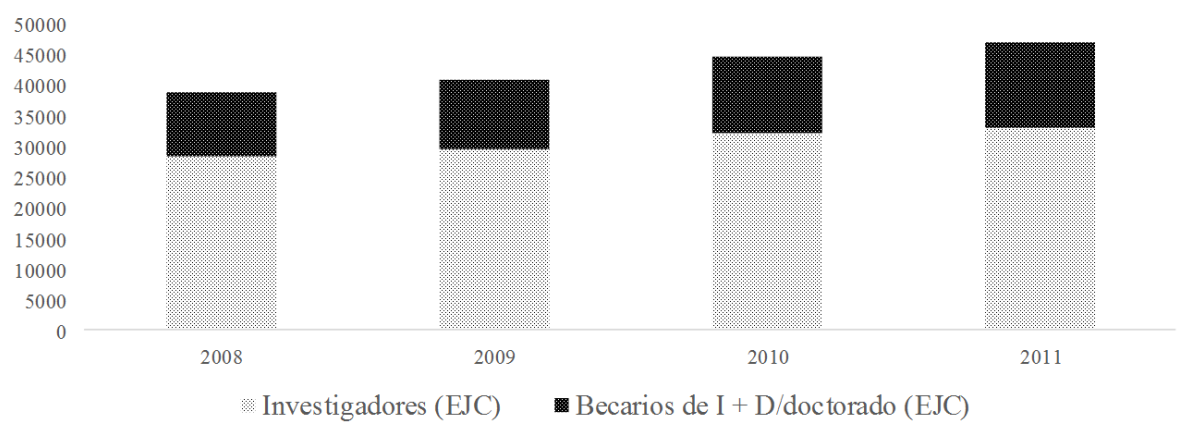

Fuente: MINCYT (2013).

El crecimiento también se registró en el porcentaje de investigadores del conjunto de la Población Económicamente Activa (PEA). Mientras en 1999 era de 2,78 en 2009 aumenta a 4,1 (Ricyt 2012). De esta forma, la política en $\mathrm{CyT}$ de este periodo, en principio, estuvo enfocada en reconstruir las capacidades científicas-tenológicas, en donde el Estado recuperó su rol de articulador del SNI a través de diferentes instrumentos y políticas de promoción de la innovación y la investigación científica y de etapas de profundización de esos instrumentos. En este marco, también se promovió el financiamiento de proyectos orientados a la articulación de los diferentes actores del SNI y se priorizó el desarrollo de sectores estratégicos como el sector software y servicios informáticos.

\section{NuEVOS INSTRUMENTOS PARA LA PROMOCIÓN DE LA INNOVACIÓN TECNOLÓGICA}

En este periodo se pueden identificar una gran variedad de instrumentos ${ }^{40}$ utilizados para implementar las políticas de ciencia, tecnología e innovación. Para fines analíticos, Albornoz (2009) los agrupa en cinco apartados, en función de sus objetivos:

- Generación de nuevo conocimiento básico y aplicado.

40 Muchos de estos instrumentos se corresponden con el patrón difundido por el BID (Banco Interamericano de Desarrollo) y el Banco Mundial, en el menú de cuyos préstamos para la ciencia y tecnología tal conjunto instrumental está generalmente comprendido. 
- Formación de recursos humanos en ciencia, tecnología e innovación.

- Generación de redes que articulen sistemas de innovación.

- Generación de nuevos productos y servicios de alto valor agregado.

- Desarrollo de áreas tecnológicas estratégicas para el país (Albornoz 2009: 68).

En Argentina, se han puesto en práctica instrumentos en los cinco apartados mencionados y la financiación de estas actividades proviene mayoritariamente de fondos públicos. En términos generales, casi las dos terceras partes son sostenidas por el presupuesto público y la mayor parte de los instrumentos son administrados por la Agencia Nacional de Promoción Científica y Tecnológica (ANPCyT). Si bien, la ANPCyT fue creada en la década de 1990 con un estilo de financiamiento novedoso que separaba la promoción de la ejecución de los fondos públicos orientados al desarrollo científico-tecnológico, en la actualidad este organismo constituye un componente central del sistema para la promoción de la investigación científica y la innovación tecnológica. Su rol fundamental se observa en la variedad y ampliación de los instrumentos ofertados en este periodo, como así también en su evolución. A fines de la década de 1990, la agencia administraba no más de seis instrumentos, mientras que en la actualidad son más de quince.

Los instrumentos de promoción y financiamiento de la innovación están orientados, por un lado, a apoyar proyectos dirigidos al mejoramiento de la productividad del sector privado a partir de la innovación tecnológica (FONTAR) ${ }^{41}$, financiar proyectos de investigación cuya finalidad es la generación de nuevos conocimientos científicos y tecnológicos (FONCYT), promover la creación y consolidación de nuevas empresas en el sector software (Fondo Fiduciario de Promoción de la Industria del Software, FONSOFT) y apoyar proyectos y actividades cuyo objetivo sea desarrollar capacidades críticas en áreas de alto impacto potencial y transferencia al sector productivo (FONARSEC). De estos fondos se desprenden un conjunto más amplio de instrumentos de financiamiento.

Asimismo, las políticas e instrumentos fueron evolucionando paulatinamente, en una primera etapa se implementaron instrumentos públicos de corte horizontal ${ }^{42}$ cuyo objetivo estuvo relacionado a promover la

41 Fue creado en 1995, y tenía como objetivo financiar, a través de fondos internacionales, los proyectos de modernización tecnológica de PYMEs industriales e instituciones públicas de ciencia y tecnología.

42 En rasgos generales, la principal distinción que hace la CEPAL (2007) entre las políticas de intervención horizontal y vertical es que las primeras están orientadas a incentivar la innovación en el conjunto del entramado productivo sin discriminar 
producción de bienes con mayor contenido de conocimiento e innovación. Esta estrategia trataba de ampliar y diversificar la cobertura de eventuales beneficiarios atendiendo a consideraciones de impacto (Porta y Lugones 2011). La diversificación de los instrumentos fue una condición clave para implementar políticas en donde la heterogeneidad de las problemáticas del sector privado era la regla y en este campo se delinearon diferentes escenarios (Peirano 2011) En este sentido, los instrumentos del FONTAR se combinaron para financiar diferentes aspectos o etapas del proceso innovador de la firma, desde las actividades propias de la fase inicial de los desarrollos tecnológicos (gastos de $\mathrm{I}+\mathrm{D}$, creación de unidades de $\mathrm{I}+\mathrm{D}$, desarrollo de nuevos productos, materiales, procesos o servicios, realización de ensayos, prototipos o pruebas piloto), hasta los gastos necesarios para alcanzar escala industrial.

\section{DESARROLLO DE ÁREAS TECNOLÓGICAS ESTRATÉGICAS PARA EL PAÍS: EL CASO DEL SECTOR SOFTWARE Y SERVICIOS INFORMÁTICOS}

El presente apartado tiene como finalidad analizar una experiencia concreta en donde la implementación de una política científico-tecnológica bien orientada permitió el crecimiento y despegue de un sector estratégico vinculado al conocimiento como el sector software y servicios informáticos (SSI en adelante). En este marco, los principales objetivos que guían esta sección se orientan a comprender el rol que tuvieron los instrumentos de política en ciencia, tecnología e innovación implementados a escala nacional con el objetivo de promover el SSI. Desde esta perspectiva, el apartado comienza con un breve diagnóstico del sector software en el periodo neoliberal, a continuación se indaga en las políticas sectoriales que se implementaron a partir del año 2003, y por último se intenta relacionar los incentivos implementados con el crecimiento y desempeño del sector en este periodo. En este sentido, se pudo corroborar que el SSI tuvo un crecimiento sostenido en los últimos ańos y que el acceso a los instrumentos de políticas estudiados tuvo un efecto positivo sobre el desempeño de las empresas de SSI. Para ello, se indagó en las empresas que reciben ayuda estatal a través de los diversos instrumentos propuestos para el sector y aquellas que no, sobre todo analizando tamańo de empresa beneficiada, la dinámica del empleo entre unas y otras y la importancia de la ocupación

por áreas o sector y parten de la igualdad de condiciones. Por su parte, las políticas verticales intentan promocionar algún sector específico y/o regional y tienen como objetivo direccionar la aplicación de recursos para alentar la innovación a nivel sectorial y promover la articulación entre la oferta y la demanda. Sobre todo, estas políticas buscan incentivar la cooperación y articulación entre universidades, centros de investigación y empresas y se focalizan en áreas estratégicas. 
del sector de SSI respecto a otras actividades productivas y de servicios.

\section{Sector Software y Servicios Informáticos en la década NEOLIBERAL}

En la Argentina, la década de 1990 estuvo signada por la ausencia de políticas específicas y sistemáticas para la promoción de la industria del software (Yoguel, Lugones y Sztulwark 2007). El instrumento que más se aproximó a una política de incentivo para el sector fue el FONTAR, sin embargo, los fondos no eran direccionados a sectores específicos y, por lo tanto, las empresas beneficiadas eran mayoritariamente manufactureras. Entre 1995 y 2001, el FONTAR aprobó un total de 778 proyectos correspondientes a 850 empresas entre sus diferentes líneas de apoyo financiero, prevaleciendo el acceso a crédito fiscal y a consejerías tecnológicas ${ }^{43}$ dedicadas a la asistencia técnica (Borrastero 2014).

En este marco, a comienzos del año 2000 los diagnósticos sobre la dinámica del SSI en Argentina eran fuertemente negativos. Como señala Barletta et al. (2014: 12):

[...] nadie pronosticaba que una década después el empleo en el sector iba a ser $8 \%$ superior al empleo del complejo automotriz, superior a los ocupados en diversos sectores primarios (servicios agrícolas), industriales (bienes de capital, cuero y calzado, madera, muebles, siderurgia) y de servicios (electricidad, gas y agua).

Diversos trabajos publicados ponían de manifiesto que los problemas que enfrentaba el sector limitaban su sendero evolutivo. Estas restricciones se centraban en tres cuestiones: 1) capacidades comerciales excesivamente focalizadas en el mercado interno que bloqueaban la posibilidad de desarrollar una industria competitiva en los mercados externos (López y Ramos 2007, 2008); 2) débil desarrollo de las capacidades tecnológicas de los trabajadores que condicionaba el grado de complejidad de los productos y servicios ofertados; y 3) ausencia de una masa crítica de firmas de excelencia que desarrollen productos propios, lo que limitaba la posibilidad de identificar perfiles sectoriales exitosos (Chudnovsky, López y Melitzko 2001, López 2003). Sin embargo, las evidencias de los 2000 pusieron de manifiesto que, a pesar de estas restricciones, el sector tomó un sendero muy distinto y fue solucionando endógenamente y con ayuda de diversos instrumentos de apoyo las principales restricciones (Barletta et al. 2014). En efecto, desde la devaluación del peso argentino en 2002

43 Las consejerías tecnológicas es un instrumento del FONTAR destinado al financiamiento de proyectos de consejerías tecnológicas que busquen el fortalecimiento tecnológico de las pequeñas y medianas empresas. 
las firmas de SSI protagonizaron un crecimiento vertiginoso, con una dinámica agregada caracterizada por incrementos en el empleo, las ventas y las exportaciones muy superiores al crecimiento registrado por la industria manufacturera (Barletta et al. 2013, Maldonado et al. 2013).

Una serie de factores permitirían explicar este favorable desempeño, entre los que se destacan: la mayor competitividad de la economía argentina a partir de la devaluación de principios del 2002, la generalización del outsourcing ${ }^{44}$ en el desarrollo de software a nivel global (que permitió dinamizar un segmento importante de las firmas de SSI) y otras características culturales y contextuales favorables a la inserción externa (como, por ejemplo, disponibilidad de recursos humanos calificados, entre otros). Estos factores se complementaron con otros de naturaleza interna como el fuerte crecimiento del mercado doméstico, un elevado nivel de capacidades generadas en décadas previas en las firmas más antiguas y en la gran mayoría de nuevas firmas desde los 2000; y, una amplia batería de programas públicos tendientes a promover la actividad exportadora y las actividades de I+D que motorizaron los esfuerzos de innovación.

\section{SECTORSOFTWAREYSERVICIOS INFORMÁTICOSEN LA POSCONVERTIBILIDAD}

A partir de las tendencias esbozadas anteriormente, a principios del año 2003 se comenzó a visualizar la posibilidad de impulsar el crecimiento del sector de software a través de políticas específicas.

\section{Políticas e instrumentos de promoción sectorial}

El primer paso en dirección al fortalecimiento del sector en este periodo fue la sanción de la Ley N. ${ }^{\circ} 25.856$, el 4 de diciembre de 2003, que establece a la producción de software como actividad pasible de promoción y se anticipa así a la creación de un instrumento sectorial específico, la Ley Nacional N. ${ }^{\circ} 25.922$ de Promoción de la Industria del Software. Dicha Ley establece beneficios especiales para esta industria: exención por diez años de los impuestos industriales; crédito fiscal de hasta un $70 \%$ para cancelar el IVA y otros impuestos nacionales; desgravación del 60\% sobre el impuesto a las ganancias para las empresas que acrediten $\mathrm{I}+\mathrm{D}$; certificaciones de calidad y exportaciones de software; desgravación de la importación de hardware para la producción. Se excluyen las restricciones a la importación de productos informáticos necesarios para la producción de software (por ejemplo, hardware).

44 Es el contrato que una empresa realiza a otra para que ésta lleve a cabo determinadas tareas que, originalmente, estaban en manos de la primera. 
A su vez, el Decreto explicita que las políticas que involucra la Ley de Software surgen de los lineamientos generales del Plan Estratégico de Software y Servicios Informáticos 2004-2014, que se elaboró en el marco del programa de foros nacionales de competitividad industrial de las cadenas productivas creado en 2003. Dicho programa incluyó a la industria de software y servicios informáticos como una de las nueve cadenas productivas estratégicas para el desarrollo de la economía nacional, por lo cual se constituyó el Foro de Software y Servicios Informáticos, del que participaron funcionarios públicos, representantes de las entidades del sector, empresarios y académicos. Como producto del foro se elaboró un plan estratégico sectorial a diez años con la visión de constituir a la Argentina, como un actor relevante del mercado mundial de software y servicios informáticos hacia mediados de la década de 2010. Para ello se definieron diversas estrategias que comprenden: el impulso a las exportaciones, la ampliación del mercado interno, al desarrollo de los recursos humanos, de la calidad, de la asociatividad, del marco jurídico y del financiamiento, a partir de una fuerte intervención estatal en estos campos y de la articulación público-privada. A partir de aquel momento se fortalecieron gradualmente distintas políticas de refuerzo de la Ley de Software, orientadas sobre todo al financiamiento de las PYMEs del sector.

Asimismo, junto con la Ley, se creó en 2004, en el ámbito de la ANPCYT, el FONSOFT ${ }^{45}$, con el objetivo de financiar diferentes actividades del sector a través de créditos y subsidios provenientes del presupuesto nacional y administrado por la agencia. Aproximadamente en el mismo periodo, el FONTAR comenzó a financiar con asiduidad proyectos de innovación presentados por PYMEs de software, dando lugar a un proceso en el cual una porción de los créditos, subsidios y crédito fiscal otorgados para $\mathrm{I}+\mathrm{D}$, modernización tecnológica y gastos de patentamiento, entre

45 El FONSOFT ofrece tres tipos de instrumentos: 1) aportes no reembolsables (ANR), es decir: subsidios a las PYMEs productoras de software para el desarrollo de tres tipos de actividades: la certificación de calidad, el desarrollo de nuevos productos o procesos y la $\mathrm{I}+\mathrm{D}$; bajo esta modalidad las empresas deben ofrecer una contraparte equivalente de recursos propios, entre los cuales se contabiliza la masa salarial. Para cualquiera de las tres actividades pasibles de financiación se otorga prioridad a las empresas de menor escala económica, y en algunos casos a las empresas asociadas, a los proyectos destinados a ciertas áreas consideradas estratégicas (como videojuegos y agroindustria, entre otras) y a las que muestran mayores grados de innovación; 2) la línea Emprendedores, un subsidio específico para las micro y pequeñas empresas nuevas (de menos de dos años de antigüedad); y 3) la línea de créditos Exporta, destinados a la iniciación o consolidación de la actividad exportadora de las empresas, mediante la financiación del $80 \%$ de los gastos en asistencia técnica, capacitación, promoción externa y todas las actividades vinculadas, a tasas bajas por el plazo de doce meses y con periodos de gracia. 
otros, que este fondo financia comenzaron a destinarse a PYMEs de software con las competencias necesarias para el desarrollo de proyectos de mayor complejidad ${ }^{46}$. En la actualidad, la Ley de Software y los dos fondos mencionados constituyen las políticas nacionales de fomento sectorial más específicas y relevantes, con una amplia cobertura. Sumado a ello, desde la visión del Estado nacional la cadena de valor del software se ha consolidado como estratégica, adoptando un lugar de relevancia en el Plan Estratégico Industrial 2020, en particular a raíz de su potencial en términos de empleo y exportaciones y para posibilitar de modo transversal mejoras en productos y procesos de todas las ramas productivas.

\section{Desempeńo general del sector software y servicios informáticos}

En términos generales, según datos del Observatorio Permanente (OPSSI) de la Cámara de Empresas de Software y Servicios Informáticos (CESSI) para el periodo 2003-2011 las ventas de software argentino al exterior crecieron en 340\%. Además, en 2011 aumentó la facturación un $20 \%$ al pasar de US\$2.582.000.000 en 2010 a US\$ 3.102.000.000 en 2011 y se generaron 10.000 nuevos puestos de trabajo para alcanzar un total de 70.000 empleados en el sector, cuando en 2003 eran de apenas 20.000. Por otra parte, se constata la existencia de un conjunto de PYMEs del sector de software y servicios informáticos relativamente joven.

\section{Tabla 3: Resumen de los principales indicadores para el sector software y servicios informáticos}

\begin{tabular}{ccc} 
Indicador & $\mathbf{2 0 0 3}$ & $\mathbf{2 0 1 1}$ \\
\hline Fuerza Laboral (miles) & 20 & 70 \\
Ventas (US\$ billones) & 0,83 & 2,97 \\
Firmas (miles) & - & 2,4 \\
$\begin{array}{c}\text { Porcentaje de PYMEs sobre el total } \\
\text { Porcentaje de empresas desarrolladoras }\end{array}$ & - & - \\
de software & - & - \\
Exportaciones (US\$ millones) & 170 & 792 \\
& Fuente: CESSI (2012).
\end{tabular}

El 38,5\% de las PYMEs de este sector inició sus actividades después de 2002, tras la devaluación del peso y el inicio de la recuperación económica. Cabe destacar que estas empresas pequeñas para el 2008 constituían el 53,4\% del universo de firmas del sector. (Observatorio PYME 2008). Asimismo, vale la pena mencionar también que para 2009, el sector de

46 En el periodo 2003-2010, la agencia aprobó 4.183 proyectos entre los diferentes instrumentos de FONTAR por un total de US\$1.344.000, representando el fondo de financiamiento con la mayor tasa de proyectos aprobados y con los montos más altos. 
software en la Argentina ya representaba 0,74 puntos del PBI del país (IERAL 2011).

\section{Tabla 4: Porcentaje de la ocupación del sector de SSI respecto a otras actividades productivas y de servicios, 1998, 2002 y 2013}

\begin{tabular}{cccc} 
Sector & $\mathbf{1 9 8 8}$ & $\mathbf{2 0 0 2}$ & $\mathbf{2 0 1 3}$ \\
\hline Agricultura y ganadería & 8 & 10 & 27 \\
Servicios agropecuarios & 149 & 135 & 236 \\
Extracción de petróleo y gas & 95 & 96 & 171 \\
Alimentos & 7 & 10 & 24 \\
Textiles y confecciones & 22 & 35 & 76 \\
Cuero y calzado & 56 & 79 & 200 \\
Madera & 79 & 121 & 200 \\
Maquinaria y equipo & 42 & 66 & 121 \\
Complejo automotor & 35 & 61 & 108 \\
Muebles & 63 & 121 & 124 \\
Siderurgia & 57 & 85 & 127 \\
Electricidad, gas y agua & 53 & 63 & 175 \\
Construcción & 7 & 18 & 19 \\
Bancos e Intermediarios & 23 & 34 & 91 \\
Servicios Inmobiliarios & 17 & 23 & 92 \\
Seguros & 41 & 55 & 72 \\
Cine, radio y TV & 40 & 45 & 76
\end{tabular}

Fuente: Ministerio de Trabajo.

Como muestra la Tabla 4 también se advierte el aumento significativo del peso del sector software en relación al empleo de casi todos los sectores. En especial, es interesante destacar que en 2013 este sector pasa a ocupar más personal que otros sectores que tenían un empleo mayor en 1998 (extracción de petróleo y gas, cuero y calzado, madera, maquinaria y equipo, complejo automotor, muebles, siderurgia, electricidad, gas y agua, sector financiero). A la vez, se achica significativamente la brecha respecto a otros sectores como agricultura y ganadería, alimentos, textiles e indumentaria, construcción; sector financiero, servicios inmobiliarios, seguros y cine y TV.

\section{Una aproximación al impacto de las políticas sectoriales en el desarrollo del sector software y servicios informáticos}

Como se adelantó en los párrafos anteriores, esta sección tiene como finalidad comprender el impacto de los instrumentos sectoriales en el desarrollo y crecimiento del sector software. En este sentido, podemos destacar que las empresas reciben ayuda de los tres instrumentos descriptos anteriormente, sin embargo el FONSOFT es el fondo que mayor cobertura 
ha desplegado, de un total de 256 empresas el FONSOFT proveyó subsidios a un $37,50 \%$.

Tabla 5: Empresas que reciben ayuda estatal, según tipo de instrumento, 2012

Cobertura de las Total de

\begin{tabular}{ccc} 
Instrumentos & políticas & empresas \\
\hline Ley de Software & $24,61 \%$ & 256 \\
FONSOFT & $37,50 \%$ &
\end{tabular}

FONTAR $\quad 17,58 \%$

Fuente: Eláboración propia basada CESSI (2012).

Asimismo, como se advierte en la Tabla 5, el financiamiento otorgado por estos fondos involucra en conjunto al $22 \%$ de las firmas con más de 5 ocupados. En cuanto a la distribución por localización geográfica las empresas más beneficiadas son las de Córdoba (38\%), seguidas por las firmas santafesinas (30\%) y por las de la ciudad de Buenos Aires (21\%).

Tabla 6: Distribución según subsidio y localización No Porcentaje

Localización beneficiarias Beneficiarias de empresas

$\begin{array}{cccc}\text { Partidos del Gran } & & & \\ \text { Buenos Aires } & 83 & 13 & 14 \\ \text { Capital Federal } & 902 & 246 & 21 \\ \text { Buenos Aires } & 45 & 10 & 18 \\ \text { Córdoba } & 64 & 40 & 38 \\ \text { Santa Fe } & 65 & 28 & 30 \\ \text { Otros } & 110 & 18 & 14 \\ \text { Total } & 1269 & 355 & 22\end{array}$

Fuente: Base para el Estudio de la Dinámica del Empleo (BADE), Ministerio de Trabajo.

Por su parte, si analizamos entre asignación de beneficios y tamaño de la firma los datos revelan que las empresas que ocupan entre 50 y 300 personas fueron las más beneficiadas $(45 \%$ y $38 \%$ respectivamente frente al $22 \%$ del total). 


\section{Tabla 7: Distribución por subsidio y tamaño de empresa}

Porcentaje de

Localización No beneficiarias

Beneficiarias beneficiarias

Entre 5 y 10

Entre 11 y 50

Entre 51 y 100

Entre 101 y 300

Mas de 300

Total
572

566

71

48

12

1.269
73

195

43

39

5

355
Fuente: $\stackrel{22}{\text { BADE }}$, Ministerio de Trabajo.

En relación a la evolución del empleo se puede señalar que la tasa de crecimiento acumulado fue superior entre las empresas beneficiarias (369\% entre 2003 y 2010) en relación al crecimiento registrado por las firmas sin beneficios que se ubica en un $280 \%$ acumulado.

Tabla 8: Evolución del empleo en firmas con diferentes beneficios (en puestos de trabajo), 2003-2010

\begin{tabular}{ccccccccc} 
Beneficios & $\mathbf{2 0 0 3}$ & $\mathbf{2 0 0 4}$ & $\mathbf{2 0 0 5}$ & $\mathbf{2 0 0 6}$ & $\mathbf{2 0 0 7}$ & $\mathbf{2 0 0 8}$ & $\mathbf{2 0 0 9}$ & $\mathbf{2 0 1 0}$ \\
\hline $\begin{array}{c}\text { Solo } \\
\text { MINCYT }\end{array}$ & 1.073 & 1.807 & 2.536 & 3.324 & 4.448 & 5.725 & 6.143 & 6.336 \\
$\begin{array}{c}\text { Solo Ley de } \\
\text { Software }\end{array}$ & 900 & 1.240 & 1.794 & 2.580 & 3.095 & 3.612 & 4.034 & 4.941 \\
Ambas & 1.974 & 2.712 & 3.592 & 4.864 & 7.595 & 6.669 & 5.683 & 7.245 \\
Total & 3.947 & 5.759 & 7.922 & $\begin{array}{c}10.768 \\
\text { Fuente: BADE, Ministerio de Trabajo. }\end{array}$
\end{tabular}

En este sentido, es dable interpretar que la industria de software $y$ servicios informáticos ha tenido un crecimiento sustancial en los últimos años producto de políticas de promoción del sector que bajo el encuadre normativo de la Ley de Software buscaron impulsar la creación de empresas, su competitividad interna y consecuentemente su inserción internacional. En este último punto, podemos señalar que su carácter de exportador neto de servicios informáticos es indicativo de condiciones de competitividad en el mercado internacional. Como se puede advertir en la Tabla 9, a partir del año 2003 el balance comercial de los servicios informáticos e información comienza a ser positivo y esta tendencia se mantiene y aumenta a lo largo de todo el periodo. 


\section{Tabla 9: Estimación del Balance de Pagos. Servicios de Informática e Información, 2001-2013 (en millones de dólares)}

\begin{tabular}{lccccccccccccc} 
& $\mathbf{2 0 0 1}$ & $\mathbf{2 0 0 2}$ & $\mathbf{2 0 0 3}$ & $\mathbf{2 0 0 4}$ & $\mathbf{2 0 0 5}$ & $\mathbf{2 0 0 6}$ & $\mathbf{2 0 0 7}$ & $\mathbf{2 0 0 8}$ & $\mathbf{2 0 0 9}$ & $\mathbf{2 0 1 0}$ & $\mathbf{2 0 1 1}$ & $\mathbf{2 0 1 2}$ & $\mathbf{2 0 1 3}$ \\
\hline Ingresos & 189 & 127 & 166 & 193 & 238 & 378 & 655 & 894 & 1.054 & 1.338 & 1.750 & 1.725 & 1.708 \\
Egresos & 192 & 131 & 139 & 160 & 195 & 226 & 310 & 378 & 427 & 461 & 562 & 646 & 667 \\
Saldos & -3 & -3 & 26 & 33 & 43 & 152 & 344 & 516 & 626 & $\begin{array}{l}877 \\
\text { Fuente: INDEC. }\end{array}$
\end{tabular}

Este dato no es menor ya que contrasta con la tendencia que en los últimos años han tenido las ramas industriales de mayor contenido tecnológico que presentan déficit cada vez más agudos. Esto marca la pauta que cuando se articulan incentivos fiscales y tecnológicos se pueden desarrollar sectores con gran dinamismo e inserción internacional mostrando de esta forma avances concretos en la reversión del cuadro de dependencia tecnológica.

\section{CONCLUSIONES}

A la traumática crisis económica, social y política que derivara en el abandonó del régimen de convertibilidad en enero de 2002, le sucedió el período de crecimiento económico más prolongado y dinámico de la historia del capitalismo argentino. La implementación de un nuevo patrón monetario sostenido en el dólar alto, con la consecuente recuperación de las condiciones de competitividad de las actividades productoras de bienes transables, motorizó el desarrollo de una fase expansiva de la dinámica de acumulación de capital del sector industrial que opera en el espacio nacional.

Como corolario de lo anterior, durante el período de la posconvetibilidad se ha visto revertido el movimiento desindustrializador abierto por la última dictadura militar, cuya profundización se vehiculizó con la implementación de políticas de ajuste estructural, apertura y liberalización económica en un escenario de sobrevaluación cambiaria en la década de 1990. En virtud de ello, la industria manufacturera ha recuperado su centralidad en la dinámica de crecimiento, cumpliendo un rol protagónico en la recuperación del empleo, los salarios y de los indicadores sociodistributivos durante la última década. Sin embargo, como se ha visto, el crecimiento productivo carga aún con buena parte de los lastres cualitativamente regresivos del neoliberalismo industrial: un perfil de especialización que continúa fuertemente anclado en la explotación de ventajas naturales (ramas agroalimentarias) y actividades receptoras de patrones tecnológicamente consolidados (procesamiento de metales, química básica, sector automotriz), sumado a ello una matriz productiva desarticulada que mantiene fuertes carencias en sus casilleros más complejos (industria productora de bienes de capital). 
Sin lugar a dudas, las transformaciones apreciables del patrón de acumulación constituyen un marco general mucho más favorable para el despliegue de las potencialidades de una activa política estatal en la promoción de la investigación científica orientada al desarrollo productivo. Como se ha visto, a partir del 2003 y desde la creación del MINCYT en 2007, se avanzó en distintos aspectos, en principio, se priorizó el desarrollo y promoción de sectores estratégicos, y se pasó desde una política horizontal en materia de innovación y financiamiento hacia una política de alcance vertical. Así, se promovió el financiamiento de proyectos orientados a la articulación de los diferentes actores del sistema nacional de innovación, entre ellos centros de investigación, universidades y empresas. Como así también, se promovió la creación de PYMEs de base tecnológica a través de regímenes de promoción e incentivos fiscales con un marcado perfil innovativo.

En este marco, la profundización de los esfuerzos del Estado buscaron recomponer las capacidades científicas tecnológicas fuertemente agredidas por en la década previa, para ello se focalizaron políticas tendientes a la formación de recursos humanos y el incremento de la inversión pública en ciencia y tecnología. Todo ello facilitó la estructuración de un sistema científico tecnológico con mayor nivel de articulación entre sus componentes, las universidades públicas, y sus núcleos de investigación, y el sector productivo.

Como se ha demostrado a lo largo del trabajo, las trasformaciones sucedidas desde el colapso y repliegue de las fuerzas neoliberales en la Argentina han configurado condiciones para el establecimiento de una nueva armonía en las relaciones entre desempeño productivo y política científico-tecnológica. Como reconoce Cimoli et al. "disponer simplemente de una política científica y tecnológica bien diseñada y pragmática no es una garantía suficiente de eficacia en materia de innovación y de mejora de la capacidad tecnológica" (2007: 37). Si hay un aprendizaje siempre oportuno de recuperar de la experiencia neoliberal argentina es la notoriedad de la falacia que pregona la capacidad mercado como asignador justo y eficiente de los recursos con los que cuenta un país. El achicamiento de la brecha entre política tecnológica y transformación industrial no puede sostenerse en las posibilidades de derrame de las condiciones macroeconómicas favorables.

Si las transformaciones ocurridas desde la salida de la convertibilidad permiten hablar de una nueva armonía entre desempeño productivo y política científico tecnológica, donde la primera constituye un indispensable escenario para el despliegue de las segunda, se aprecia como necesidad imperiosa la concentración de las energías estatales en la capitalización de esas novedosas condiciones sobre la base de una política científica industrial 
y tecnológica con horizonte en la superación de los legados tecnológicos más regresivos del capitalismo neoliberal en el país. La potenciación estatal de la nueva dinámica de expansión del sector manufacturero hacia sectores con mayores requerimientos en términos de calificación del trabajo y capacidad de generación de encadenamientos productivos virtuosos constituye una tarea ineludible para el desarrollo. 


\section{REFERENCIAS}

Albornoz, M. (2009). Desarrollo y Políticas Públicas en Ciencia y Tecnología en América Latina RIPS. Revista de Investigaciones Políticas y Sociológicas, 8 (1), 65-75.

Azpiazu D., Basualdo E. y Schorr, M. (2001). La Industria Argentina durante los Años Noventa: Profundización y Consolidación de los Rasgos Centrales de la Dinámica Sectorial Post-Sustitutiva. Buenos Aires: Área de Economía y Tecnología de la FLACSO.

Azpiazu, D., Basualdo, E. y Khavisse, M. (2004). El Nuevo Poder Económico en la Argentina de los Años 80. Buenos Aires: Legasa.

Azpiazu, D. y Manzanelli, P. (2011). Reinversión de Utilidades en un Grupo Selecto de Grandes Firmas (1998-2009). Revista Realidad Económica, 257, 56-81.

Azpiazu, D. y Nochteff, H. (1995). El Desarrollo Ausente. Restricciones al Desarrollo, Neoconservadurismo y Élite Económica en la Argentina. Ensayos de Economia Política. Buenos Aires: Tesis/Norma.

Azpiazu, D. y Schorr, M. (2010). Hecho en Argentina. Industria y economía, 1976-2001. Buenos Aires: Siglo XXI Editores.

Barletta, F, Pereira, M., Robert V. y Yoguel, G. (2013). Capacidades, Vinculaciones, y Performance Económica. La Dinámica Reciente del Sector de Software y Servicios Informáticos en Argentina. ECLAC Journal, 110.

Barletta, F, Pereira M y Yoguel, G. (2014). Impacto de la Política de Apoyo a la Industria de Software y Servicios Informáticos. Buenos Aires: MINCYT.

Basualdo, E. (2006). La Reestructuración de la Economía Argentina Durante las Últimas Décadas de la Sustitución de Importaciones a la Valorización Financiera. En Basualdo, E. y Arceo, E. (Eds.), Neoliberalismo y Sectores Dominantes. Tendencias Globales y Experiencias Nacionales. Buenos Aires: CLACSO. . (2010). Sistema Politico y Modelo de Acumulación. Tres Ensayos sobre la Argentina Actual. Buenos Aires: Cara o Ceca. 
Borrastero, C. (2014). Tipología de Empresas Innovadoras en el Sector de Software de Argentina según el Acceso a las Politicas Públicas Nacionales. Mimeo.

Boyer, R. y Saillard, Y. (1996). Teoría de la Regulación: Estado de los Conocimientos. Buenos Aires: Trabajo y Sociedad.

Burachik, G. (2010). Extranjerización de Grandes Empresas en Argentina. Problemas del Desarrollo. Revista Latinoamericana de Economia, 41 (160), 109-133.

Cámara de Empresas de Software y Servicios Informáticos de Argentina (CESSI). (2012). Reporte Semestral del Sector de Software y Servicios Informáticos de la República Argentina. Buenos Aires: CESSI.

Centro de Estudios para el Desarrollo Argentino (CENDA). (2007). La Trayectoria de las Ganancias Después de la Devaluación: La "Caja Negra" del Crecimiento Argentino. Notas de la Economía Argentina, 4, 4-13.

Centro de Investigación y Formación de la República Argentina (CIFRA). (2011). El Nuevo Patrón de Crecimiento y sus Impactos sobre la Distribución del Ingreso. Buenos Aires: CIFRA.

Cimilo, E., Lifschitz, E., Gastiazoro, E., Ciafardini, H. y Turkieh, M. (1973). Acumulación y Centralización del Capital en la Industria Argentina. Buenos Aires: Tiempo Contemporáneo.

Cimoli, M. y Dosi, G. (1995). Technological Paradigms, Patterns of Learning and Development: An Introductory Roadmap. Journal of Evolutionary Economics, 5 (3), 242-268.

Cimoli M. Ferraz, C. y Primi, A. (2007). Políticas de Ciencia y Tecnología en Economias Abiertas: La Situación de América Latina y el Caribe. Santiago: CEPAL.

Chudnovsky, D. y López, A. (1996). Política Tecnológica en la Argentina: ¿Hay Algo Más Que Laissez Faire? Revista Redes, 6, 33-75.

Chudnovsky. D., López, A. y Melitsko, S., (2001). El Sector de Software y Servicios informáticos (SSI) en la Argentina: Situación Actual y Perspectivas de Desarrollo. Buenos Aires: Centro de Investigación para la Transformación (CENIT). 
Comisión Económica para América Latina y el Caribe (CEPAL). (2007). Cinco Piezas de Politica de Desarrollo Productivo. Santiago: CEPAL.

Diamand, M. (1985). El Péndulo Argentino ¿Hasta Cuándo? Buenos Aires: Centro de Estudios de la Realidad Económica.

Freeman, C. (1993). The National System of Innovation in Historical Perspective. Cambridge Journal of Economics, 19 (1), 5-24.

Gaggero, A. (2012). La Retirada de los Grupos Económicos Argentinos durante la Crisis y Salida del Régimen de Convertibilidad. Revista Desarrollo Económico, 52 (206), 229-254.

Gonzáles F. (2011). Los Límites del Patrón de Crecimiento para la Creación de Empleo. Apuntes para el Cambio. Revista Digital de Economía Política, $1(1), 38-53$.

Herrera G. y Tavosnanska, A. (2011). ¿¿Reindustrialización en la Argentina? Una Década de Expansión Industrial en la Argentina. La Revista del CCC, 13 (54).

Instituto Nacional de Estadísticas y Censo (INDEC). (2014). Anuario Estadístico 2014. Disponible en http://www.indec.mecon.ar/

Jeffrey D. y Vial J. (2002). Competitividad y Crecimiento Económico en los Paises Andinos y en América Latina, Cambridge: Center for International Development, Harvard University.

Lindenboim J., Kennedy D. y Graña J. M. (2011). Distribución Funcional y Demanda Agregada en la Argentina. Setenta Años en Perspectiva Internacional. Buenos Aires: Universidad de Buenos Aires.

López, A. (2003). Innovación y Propiedad Intelectual en la Industria del Software y los Servicios Informáticos. Situación y Perspectivas para los Países en Desarrollo. Ponencia presentada en la Reunión Regional OMPI-CEPAL sobre el Sistema Nacional de Innovación: Propiedad Intelectual, Universidad y Empresa, 1-3 de octubre, Santiago de Chile.

López, A. y Ramos, D. (2007). Oportunidades y Desafíos para la Industria del Software en Argentina. En Bastos, T. y Silveira Marques, F. (Eds.), Desafios y Oportunidades de la Industria del Software en América Latina. Bogotá: CEPAL. 
. (2008). La Industria de Software y Servicios Informáticos Argentina. Tendencias, Factores de Competitividad y Clusters. Buenos Aires: CENIT.

Maldonado, M., Morero, H. y Borrastero, C. (2013). Catching uUp en Servicios Intensivos en Conocimiento: El caso de la Producción de Software y Servicios Informáticos de Argentina y Brasil. Revista Iberoamericana de Ciencia, Tecnología y Sociedad-CTS, 8 (24), 115-144.

Manzanelli, P. (2012). La Tasa de Ganancia en la Posconvertibilidad. Un Balance Preliminar. Revista Apuntes para el Cambio 3, 5-18.

Manzanelli, P. y Schorr, M. (2011). Extranjerización y Poder Económico Industrial en Argentina. Revista Problemas del Desarrollo, 170 (43), 3967.

Ministerio de Ciencia, Tecnología e Innovación Productiva (MINCYT). (2012). PNCTI 2012-2015. Hacia una Argentina innovadora: Plan Nacional de Ciencia, Tecnología e Innovación. Buenos Aires: Ministerio de Ciencia, Tecnología e Innovación Productiva.

- (2013). Indicadores de Ciencia y Tecnología Argentina 2011. Informe Anual. Dirección Nacional de Información Cientifica dependiente de la Subsecretaría de Estudios y Prospectiva de la Secretaría de Planeamiento y Politicas del Ministerio de Ciencia, Tecnología e Innovación Productiva. Buenos Aires: MINCYT.

Moldovan P., Gordon, A. y Di Marzo, E. (2011). Estructura Científica y Perfil Tecnoproductivo de la Argentina. En Porta F. y Lugones G. (Eds.), Investigación Cientifica e Innovación Tecnológica en Argentina. Impacto de los Fondos de la Agencia Nacional de Promoción Cientifica y Tecnológica. Bernal: Universidad de Quilmes.

Nelson, R. (1993). National Innovation Systems: A Comparative Analysis. Oxford: Oxford University Press.

Nochteff, H. (1991). Reestructuración Industrial en la Argentina: Regresión Estructural e Insuficiencia de los Enfoques Predominantes. Revista Desarrollo Económico, 123 (31), 339-358.

(1995). Los Senderos Perdidos del Desarrollo. Élite Económica y Restricciones al Desarrollo en la Argentina. En Azpiazu, D. y Nochteff, H. (Eds.), El Desarrollo Ausente. Buenos Aires: FLACSO. 
Observatorio PYME (2008). Situación y Perspectivas de las PYME del Ssector del Software y Servicios Informáticos (SSI) en la Argentina. Buenos Aires: Fundación Observatorio PYME.

Ortiz, R. y Schorr, M. (2009). Dependencia Tecnológica e industria Trunca en la Argentina de la Posconvertibilidad. Revista Industrializar Argentina, 10, 12-17.

. (2009). Evolución Reciente de la Industria Argentina de Bienes de Capital. Revista H-Industria 4 (3), 1-28.

Peirano, F. (2011). El FONTAR y la Promoción de la Innovación en Empresas entre 2006 y 2010. En Porta F. y Lugones G. (Eds.), Investigación Cientifica e Innovación Tecnológica en Argentina. Impacto de los Fondos de la Agencia Nacional de Promoción Cientifica y Tecnológica. Bernal: Universidad de Quilmes.

Pérez, C. (2012). Una Visión para América Latina: Dinamismo Tecnológico e Inclusión Social Mediante una Estrategia Basada en los Recursos Naturales. Revista Económica, 14 (2), 11-54.

Piñero, F. y Colombo, S. (2001). O Complexo Científico e Tecnológico da Argentina e do Brasil: Uma Leitura através dos Indicadores de Ciência e Tecnología. Revista Cenärios, 3 (5), 159-175.

(2002). Balance das Atividades de Cooperação Argentino-Brasileiras em Ciência e Tecnologia: 1986-2000. Revista Cadernos de Campo Pós-graduação em Sociologia. 2 (3), 1-16.

Porta F. y Bianco C. (2004). Las Visiones sobre el Desarrollo Argentino. Consensos y Disensos. Buenos Aires: Centro de Estudios sobre Ciencia, Desarrollo y Educación Superior.

Porta, F. y Fernández Bugna, C. (2011). La Industria Manufacturera: Trayectoria Reciente y Cambios Estructurales. En PNUD (Eds.), La Argentina del Largo Plazo: Crecimiento, Fluctuaciones y Cambio Estructural. Buenos Aires: PNUD.

Porta F. y Lugones, G. (Eds.). (2011). Investigación Cientifica e Innovación Tecnológica en Argentina. Impacto de los Fondos de la Agencia Nacional de Promoción Cientifica y Tecnológica. Bernal: Universidad Nacional de Quilmes. 
Poulantzas N. (2007). Poder Politico y Clases Sociales en el Capitalismo. Buenos Aires: Siglo XXI.

Red de Indicadores de Ciencia y Tecnología (RICYT). (2010). El Estado de la Ciencia. Principales Indicadores de Ciencia y Tecnología Iberoamericanos/ Interamericanos. Buenos Aires: RICYT.

Roig, A. (2008). El Desarrollo como Conflicto Institucionalizado. Revista Realidad Económica, 237, 80-92.

Rocha, F. (2012). Comentários a "Una Visión para América Latina: Dinamismo Tecnológico e Inclusión Social mediante una Estrategia Basada en los Recursos Naturales". Revista Econômica-Niterói, 14 (2), 63-72.

Rozenwurcel, G. y Bezchinsky, G. (2007). Economía del Conocimiento, Innovacióny Políticas Públicas en la Argentina. Buenos Aires: Universidad Nacional de San Martín.

Sábato, J. y Botana, N. (1968). La Ciencia y la Tecnología en el Desarrollo Futuro de América Latina. Revista de la Integración, 1 (3), 15-36.

Schorr, M. (2005). Cambios en la Estructura y el Funcionamiento de la Industria Argentina entre 1976 y 2004. Un Análisis Socio-Histórico y de Economía Politica de la Evolución de las Distintas Clases Socialesy Fracciones de Clase Durante un Periodo de Profundos Cambios Estructurales. Tesis de Doctorado, Facultad Latinoamericana de Ciencias Sociales, Buenos Aires, Argentina.

Yoguel, G., Lugones, M. y Sztulwark, S. (2007). La politica Cientifica y Tecnológica Argentina en las Últimas Décadas: Algunas Consideraciones desde la Perspectiva del Desarrollo de Procesos de Aprendizaje. Santiago: CEPAL.

Varsavsky, O. (1969). Ciencia, Política y Cientificismo. Buenos Aires: Eudeba.

Wainer, A. (2011). Más Allá del Consejo Monetario: Grandes Empresas. Problemas del Desarrollo. Revista Latinoamericana de Economía, 42 (164), 99-126.

Recibido: 27-11-2013

Aceptación de la versión final: 23-12-2015 